\title{
"Gazella" (Mammalia: Bovidae) from the late Miocene Qingyang area, Gansu, China
}

\author{
Yikun Li, Qinqin Shi, Shaokun Chen, and Tao Deng
}

\begin{abstract}
The rich collection from the late Miocene sediments from the Qingyang area, Gansu, China was discovered by E. Licent in the 1920s, and previous studies focused on the equids and hyaenids whereas little attention was given to the accompanying bovid material. The collection of Bovidae dug up from the Qingyang area and preserved at Musée Hoangho Paiho, Tianjin, China, is dominated by "Gazella". We describe and identify two species: "Gazella" paotehensis and "G." dorcadoides. The nomenclatural issues surrounding those two species of gazelles are reviewed in this paper, and although the questionable mandible illustrated by Teilhard de Chardin and Young in 1931 may be excluded from "G." paotehensis metrically and morphologically, the species is still considered valid. The subcomplete cranium M 3956, kept at Uppsala Universitet Evolutionsmuseet and studied by B. Bohlin, is selected here as the neotype of "G." paotehensis, and emended diagnoses are given. Based on previous studies and insights from new material from the Qingyang area, we provide a table summarizing diagnostic morphological characters of "G." paotehensis and "G." dorcadoides.
\end{abstract}

Yikun Li. Key Laboratory of Vertebrate Evolution and Human Origins of Chinese Academy of Sciences, Institute of Vertebrate Paleontology and Paleoanthropology, Chinese Academy of Sciences, Beijing 100044, China; University of Chinese Academy of Sciences, Beijing 100049, China; Museum für Naturkunde, Leibniz Institute for Evolution and Biodiversity Science, Berlin 10115, Germany.

liyikun@ivpp.ac.cn

Qinqin Shi. Key Laboratory of Vertebrate Evolution and Human Origins of Chinese Academy of Sciences, Institute of Vertebrate Paleontology and Paleoanthropology, Chinese Academy of Sciences, Beijing 100044, China. shiqinqin@ivpp.ac.cn

Shaokun Chen. Three Gorges Institute of Paleoanthropology, China Three Gorges Museum, Chongqing 400015, China. cskcsk2000@163.com

Tao Deng. Key Laboratory of Vertebrate Evolution and Human Origins of Chinese Academy of Sciences, Institute of Vertebrate Paleontology and Paleoanthropology, Chinese Academy of Sciences, Beijing 100044, China; CAS Center for Organic Evolution and Environment, Beijing 100044, China; Department of Earth Sciences, Nanjing University, Nanjing 210023, China. Corresponding author. dengtao@ivpp.ac.cn

Li, Yikun, Shi, Qinqin, Chen, Shaokun, and Deng, Tao. 2018. "Gazella" (Mammalia: Bovidae) from the late Miocene Qingyang area, Gansu, China. Palaeontologia Electronica 21.2.24A 1-27. https://doi.org/10.26879/838

palaeo-electronica.org/content/2018/2173-gazella-qingyang

Copyright: July 2018 Paleontological Society.

This is an open access article distributed under the terms of Attribution-NonCommercial-ShareAlike 4.0 International (CC BY-NC-SA 4.0 ), which permits users to copy and redistribute the material in any medium or format, provided it is not used for commercial purposes and the original author and source are credited, with indications if any changes are made.

creativecommons.org/licenses/by-nc-sa/4.0/ 
Keywords: "Gazella"; Bovidae; late Miocene; Qingyang

Submission: 27 November 2017 Acceptance: 10 June 2018

\section{INTRODUCTION}

Bovidae is the largest and most diverse group of Old World hoofed mammals, consisting of more than 140 extant species (Wilson and Reeder, 2005). Their significance also extends into the geological past with rich and geographically extensive fossil records over the last 18 Ma (Gentry et al., 1999; Solounias, 2007; Chen and Zhang, 2009). Especially in the late Miocene, the bovids diversified, evolved into early representatives of all extant tribes, and dispersed across Africa and Eurasia (Vrba, 1985; Bibi et al., 2009). Urmiatheriini, Caprinae, Boselaphini, and Antilopini were previously reported from the late Miocene deposits of northern China, and regarded as common elements of Chinese late Miocene mammalian assemblage (Chen and Zhang, 2009), whereas "Gazella" appears to be the only representative of the latter tribe. The research focused on Chinese "Gazella" fossils was initiated by Schlosser (1903) who described the material collected from drugstores without accurate localities or ages, and followed by Teilhard de Chardin and Young (1931) and Teilhard de Chardin and Trassaert (1938) who depicted the material discovered in Shanxi. Researches were carried forward by Bohlin $(1935,1939)$ who studied the material found in Baode, Shanxi, kept in Uppsala Universitet Evolutionsmuseet, and reignited by Chen (1997a, 1997b) who revised the material attributed to "Gazella" blacki and classified the taxa unearthed in Yushe Basin, Shanxi. Recently, Zhang and Yang (2016) described the material dug up from the Bahe formation, Shaanxi. Although fossils assigned to "Gazella" were published and described over 100 years, the monophyly of this genus and its actual phylogenetic affinities to the extant genera are still unclear, and thus when discussing extinct species, the genus name "Gazella" is here placed in quotes.

The Qingyang area is administratively attributed to Qingyang City, Gansu Province, China, since 2002, and this area is famous for the first known Paleolithic artifacts of China and the early Pleistocene Bajiazui fauna with the occurrence of Equus qingyangensis (Jia and Huang, 1985; Deng and Xue, 1999). The late Miocene deposits in the same region are even more productive and yielded hipparionine equids, hyenids, and giraffids (Qiu et al., 1979, 1987), whereas the bovid material is scattered in the faunal list and was scarcely described in previous studies (Bohlin, 1935; Teilhard de Chardin and Trassaert, 1938; Kurtén, 1951). Currently, the specimens studied by Bohlin (1935) and Kurtén (1951) are part of the Largelius Collection in Uppsala Universitet Evolutionsmuseet, but there is another larger collection made by Emile Licent (Mateer and Lucas, 1985). Taking "Gazella" species as an example, a total of seven individuals are known from the G.G. Andersson's Localities 115 and 116 (Mujiazuigou and Zhaozigou, Jiaozichuan, Qingyang) (Kurtén, 1951); however, four crania, seven maxillae, 17 mandibles, and more than 30 horn core fragments heap up in Licent Collection of Musée Hoangho Paiho, Tianjin, China. The collection still kept in Tianjin is only one part of Licent Collection, whereas the other was shipped to Paris by Licent in the 1920s and housed in the Muséum National d'Histoire Naturelle, Paris. The "Gazella" material from the Qingyang area preserved in Musée Hoangho Paiho is studied in this paper.

The Qingyang material of Licent Collection had been thought to be dug up from two localities: Xinjiagou and Zhaojiacha (Qiu et al., 1979). As shown by the red pentagrams in Figure 1, Xinjiagou is a trench scoured by the branch of Malian River, and Zhaojiacha is administratively attributed to Huachi County and was recently precisely localized $\left(36^{\circ} 14^{\prime} 52.2^{\prime \prime} \mathrm{N}, 107^{\circ} 46^{\prime} 31.3^{\prime \prime} \mathrm{E}\right)$ with the occurrence of a yet unnamed new species of rhinocerotid assigned to Chilotherium (Sun et al., personal communication, 2017). Although these localities need more stratigraphic work, the layers containing fossils are considered to be uniform and belong to the Hipparion red clay (Qiu et al., 1979; Figure 1). Two gazelle species are recognized from the collection: "Gazella" paotehensis was erected by Teilhard de Chardin and Young (1931), doubted and thoroughly discussed by Bohlin (1935, 1939), and taken as a typical late Miocene element whereas unclearly clarified by other researchers (Mi, 1943; Hooijer, 1945; Czyzewska, 1969; Chen, 1997a; Zhang et al., 2002; Zhang et al., 2013; Zhang and Yang, 2016); "G." dorcadoides was established by Schlosser (1903), considered valid by Bohlin $(1935,1939)$ but considered doubtful by Teilhard de Chardin and Trassaert (1938). Both names are reviewed here and considered as 


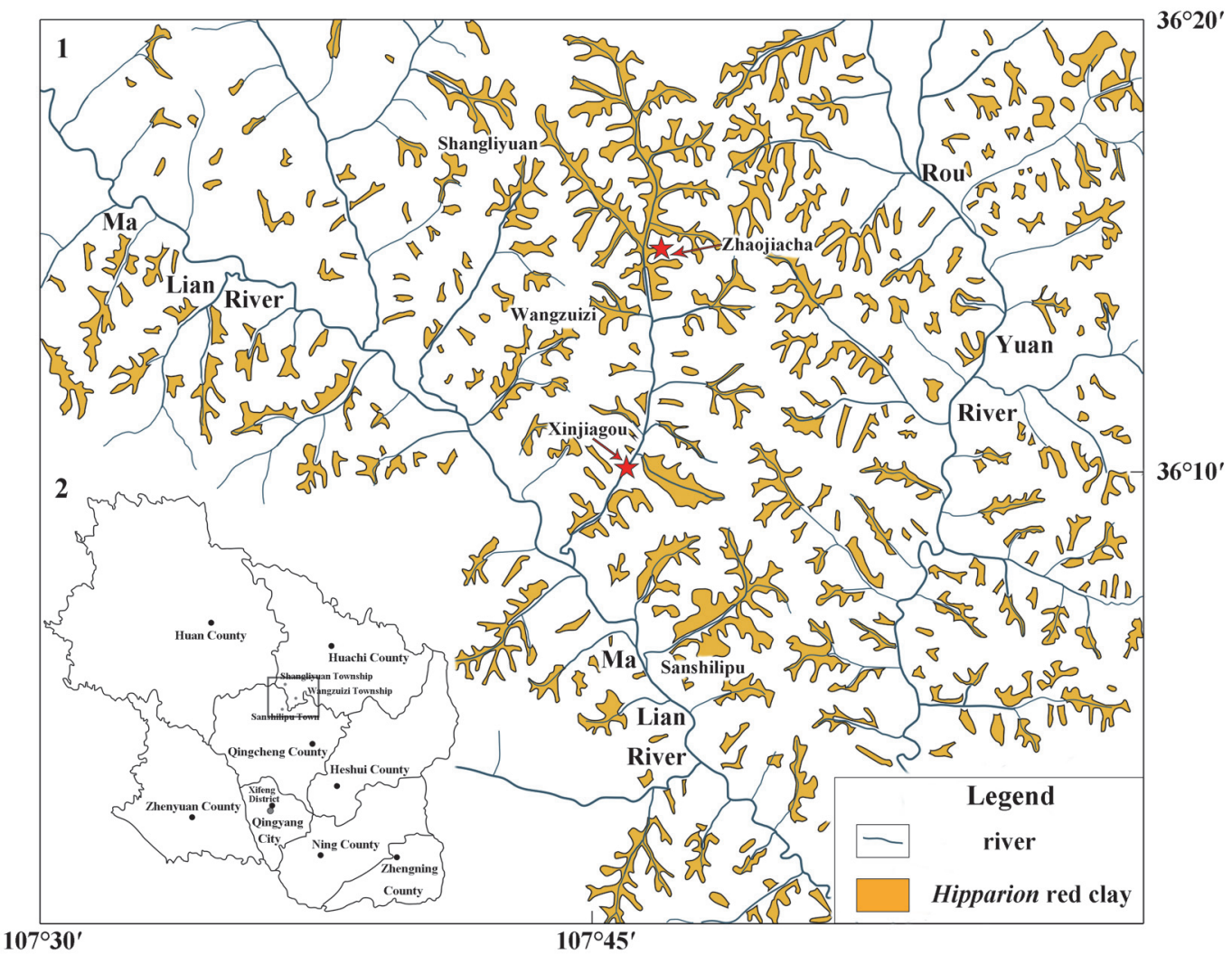

FIGURE 1. Maps of fossil localities at the Qingyang area: 1) simplified geological map (modified from the geological map of Gansu in 1981), 2) administrative zoning map.

names of valid species, and the revision of the two species contributes to the clarification of the late Miocene Hipparion fauna and the taxonomy of "Gazella" species.

\section{MATERIAL AND METHODS}

The "Gazella" material at the Qingyang area was collected by E. Licent and is kept at Musée Hoangho Paiho (117 Machang Road, Hexi District, Tianjin). Terminology and nomenclature of the skull and teeth follow Gentry (1992), Dong (2004), and Sisson (1914). Measurements follow Bohlin (1939) and Suraprasit et al. (2015) and were taken with digital calipers with a precision of $0.1 \mathrm{~mm}$.

Institution abbreviations: THP, specimen prefix of Licent Collection of Musée Hoangho Paiho, Tianjin, China; TNP, specimen prefix of Tianjin Natural History Museum, Tianjin, China (the specimens under the prefix TNP listed in this paper were also discovered by E. Licent; however, their original numbers were lost and they are newly arranged under the prefix TNP); RV, specimen prefix of Institute of Vertebrate Paleontology and Paleoanthropology, Beijing, China; $M$, specimen prefix of Uppsala
Universitet Evolutionsmuseet, Uppsala, Sweden; BSPG, specimen prefix of Bayerische Staatssammlung für Paläontologie und Geologie, Munich, Germany.

\section{SYSTEMATIC PALEONTOLOGY}

Family BOVIDAE Gray, 1821

Subfamily ANTILOPINAE Gray, 1821

Tribe ANTILOPINI Gray, 1821

"Gazella" paotehensis Teilhard de Chardin and Young, 1931

\section{Synonyms}

Gazella paotehensis in part Teilhard de Chardin and Young, 1931, Plate VII figures 2-3, pages 3638 (except the mandible in page 37 figure 5)

Gazella sp. (?=G. paotehensis) Bohlin 1935, textfigure 73 , Plate XI figure 19, Plate XII figures 1-9, pages $85-90$

Gazella gaudryi type A Bohlin, 1939, text-figures 20, 24, 48, pages 96-98

Gazella paotehensis Li, 2015, text-figures 2c, 2d, 3c, 3d, pages 551-553 
Type series. The holotype of "Gazella" paotehensis is "the frontal part of a skull, with the two horncores preserved, and a palate with the teeth belonging to the same individual" (Teilhard de Chardin and Young, 1931: page 36). And their sentence "Another palate was found with the associated lower jaw" means that a second individual, a lower jaw associated with its palate, is present and turns to be the paratype of the new species. Both the holotype and paratype lack specimen numbers, but the type localities are $\mathrm{C} / 140-\mathrm{C} / 144$, Baode County, Shanxi Province. The locality $\mathrm{C} / 144$ is interpreted as Luzigou, Baode, Shanxi (Locality 3), as indicated by the contextual information of the only specimen, an astragalus, still present in the collection of Institute of Vertebrate Paleontology and Paleoanthropology. But the astragalus is not mentioned in their original manuscript (Teilhard de Chardin and Young, 1931). The details of the other localities are unknown, and the type series are missing except for the only astragalus. Considering that the comparable type series have been lost, we therefore propose a neotype.

Neotype. M 3956, a nearly complete cranium without horn cores (Bohlin, 1939, figure 20, pages 9698; Figure 2), housed at Uppsala Universitet Evolutionsmuseet.

Type locality. Nanshawa Village, Hequ County, Shanxi Province (Andersson's locality 114S).

Emended differential diagnosis. Larger body size on average than contemporary "Gazella" gaudryi and "G." dorcadoides, and hornless in females; horn cores moderately divergent, differing from nearly parallel horn cores in "G." gaudryi or "G." dorcadoides, and moderately inclined, more upright than those of "G." dorcadoides; posterior swelling of the basal horn cores weakly present, while absent in "G." gaudryi and "G." dorcadoides; dorsal outline of the parietal of " $G$." paotehensis curved in lateral view, differing from the rapidly inclined outline of "G." dorcadoides; braincase of "G." paotehensis relatively shorter than that of "G." gaudryi; teeth of "G." paotehensis less hypsodont than that of "G." dorcadoides whereas slightly more hypsodont than that of "G." gaudryi; teeth of "G." paotehensis tending to display more developed mesostyles and metastyles in upper molars (and metastylids and entostylids in lower molars) with the compensation of the reducing development of ribs in main cusps; ratio of lower premolar to lower molar row greater than 0.60 in "G." paotehensis; and lower p4 of "G." paotehensis with an open valley between the paraconid and metaconid, whereas with a high probability (three sevenths in
Qingyang material) of the presence of a lingual stylid to form a virtually complete lingual wall.

Referred material. Three crania: TNP 00206, complete cranium without horn cores; TNP 03795, cranium slightly mediolaterally crushed with the right facial part and left brain part preserved; TNP 03871, broken cranium with frontal and partial parietal preserved; four maxillae: TNP 00205, left P3M3, right M1-M3; TNP 03093, left P2-M3; TNP 03866, left P3-M2, right P3-M3; TNP 06928, left P2-M3; seven mandibles: TNP 03855, left p2-m3; TNP 03856, left p3-m3; TNP 03857, right p4-m3; TNP 03865, left p2-m3; TNP 03876, left p3-m2; THP 06863, left p4-m3; THP 07326, left p2-m3; 22 horn cores: TNP 00203, two; TNP 03797, right; TNP 03798, right; TNP 05313, left; TNP 05315, right; TNP 05386, left; THP 05716, left; THP 05724, left; THP 06313, left; THP 06316, left; THP 06317, right; THP 06318, left; THP 06338, right; THP 06351, right; THP 06359, right; THP 06384, left; THP 06385, left; THP 06387, right; THP 06783, right; THP 06841, left; THP 07281, left; six horn core fragments: TNP 03796, TNP 05384, THP 06308, THP 06314, THP 06315, THP 06386 (Figures 3-6; Tables 1-4).

\section{Description}

Cranium. Three crania are present in the collections. TNP 00206 is the least distorted and most completely preserved, though missing both horn cores, the right zygomatic arch, and auditory bullae. TNP 00206 represents an old individual based on heavy tooth wear. TNP 03795 is mediolaterally compressed, and the left facial part and right brain portion are not preserved, with the left horn core missing its tip. TNP 03795 is an adult with teeth in moderate wear. Only the frontal and part of the parietal are preserved in TNP 03871.

The crania are medium in size, slightly larger than extant Gazella dorcas. Length of P2 to magnum foramen is $118.2 \mathrm{~mm}$ in TNP 00206. The cranium is long and slender in outline, and the maximum width of cranium is located at the caudal extremity of orbit, unfortunately without accurate measurements due to taphonomic distortion.

The premaxilla is curved and ribbon-like in profile, and contacts the nasal at the level of P2. In ventral view, the rostral portion of the premaxilla is spoon-shaped, and the palatine fissure is elongated triangular-shaped.

The nasal displays a doomed dorsal roof, and its maximum width occurs at the rear third, contiguous to the nasal process of the frontal. The nasalfrontal suture is asymmetrically M-shaped, and the 


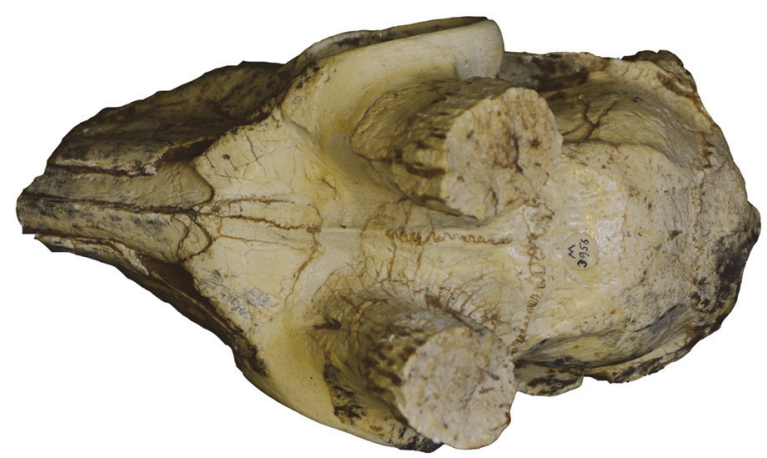

2

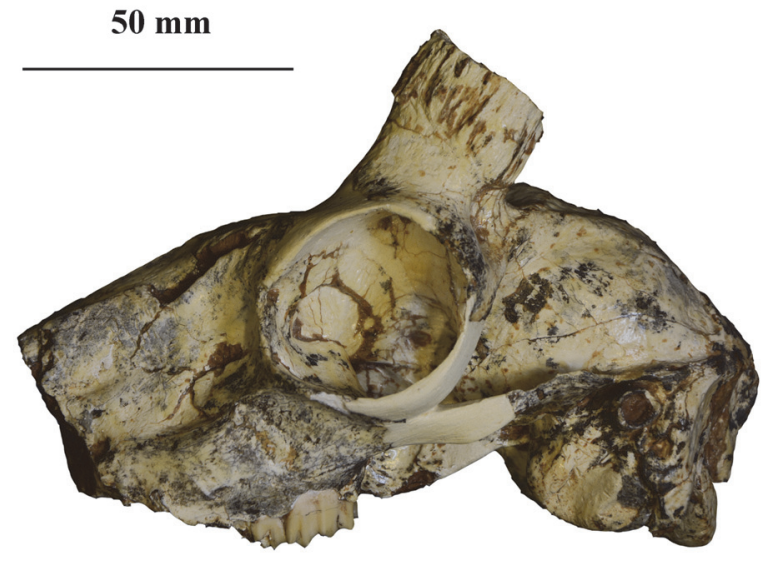

3

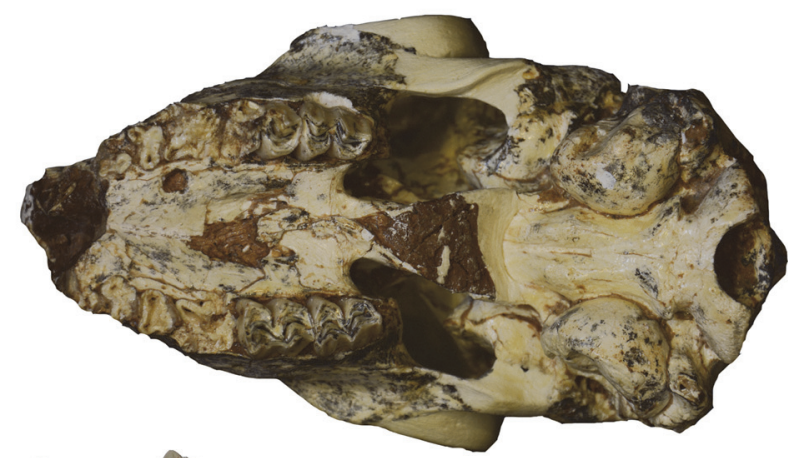

4
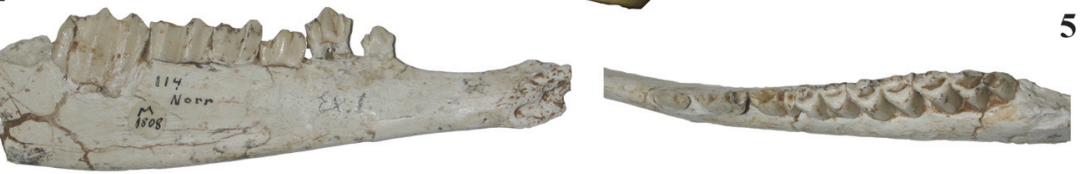

FIGURE 2. Material ascribed to "Gazella" paotehensis from Uppsala Universitet Evolutionsmuseet, M 3956, cranium, the neotype, 1) dorsal view, 2) left lateral view, 3) ventral view; M 1808, left mandible, 4) lingual view, 5) occlusal view. Scale bar equals $50 \mathrm{~mm}$.

caudal margin of the nasal is located rostrally to the frontal level of the rostral orbital rim.

The frontal area rostral to the horn pedicle is slightly sunken, whereas the interfrontal suture is complex and slightly elevated as a ridge. The ridge is highly-elevated caudally, and becomes progressively weaker towards the nasal-frontal suture. The supraorbital foramen is small and round, sunken at the lateral base of a triangular pit. The orbit protrudes moderately laterally, and its length is subequal to its height. The front edge of the rostral rim is situated at the level of the boundary between M2 and $\mathrm{M} 3$.

The frontal-parietal suture is also complex, yet flat. The parietal is quadrangular and parallel widening laterally. The temporal ridges approach cau- 


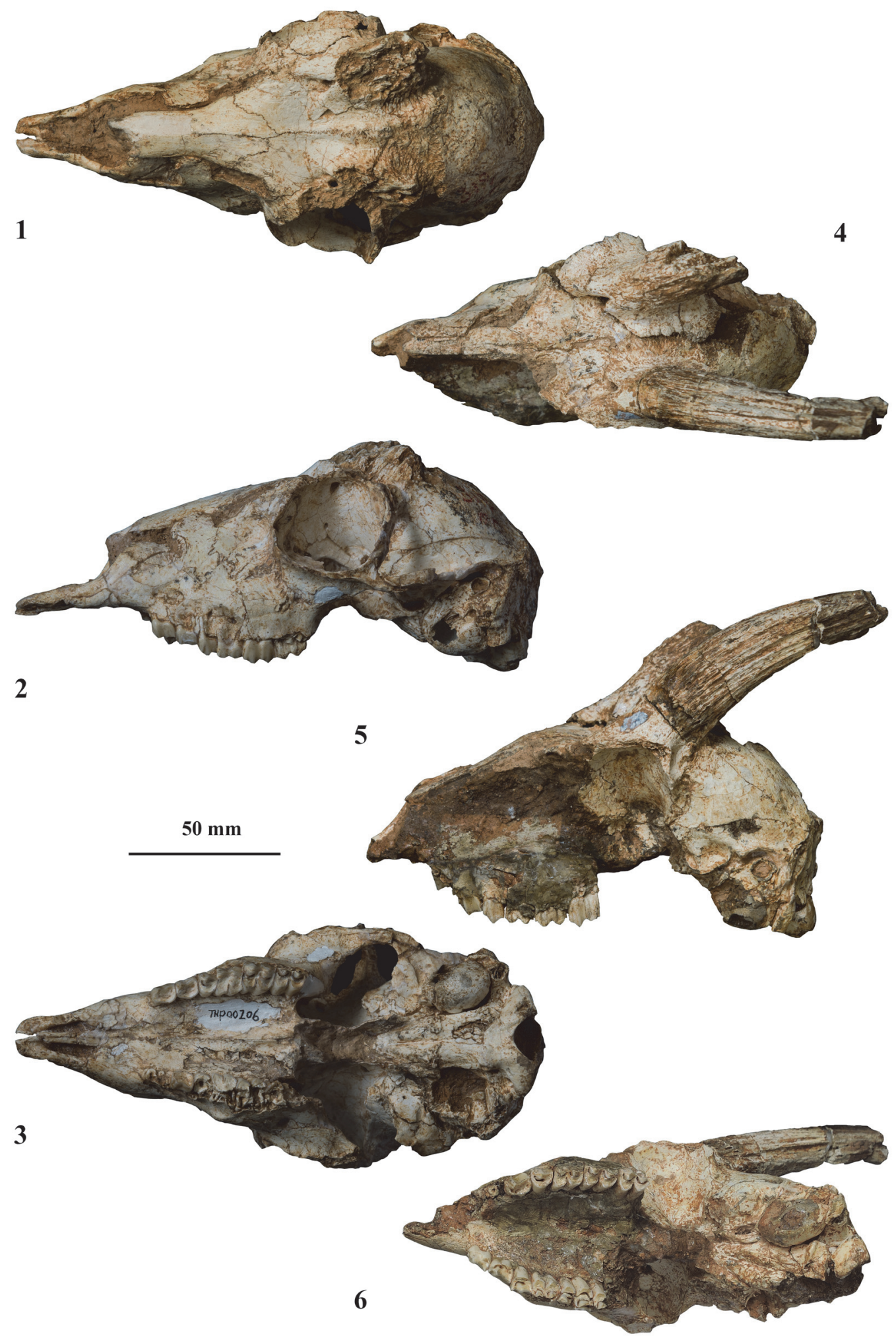

FIGURE 3. Crania ascribed to "Gazella" paotehensis from Qingyang: TNP 00206, 1) dorsal view, 2) left lateral view, 3) ventral view; TNP 03795, 4) dorsal view, 5) left lateral view, 6) ventral view. Scale bar equals 50 mm. 


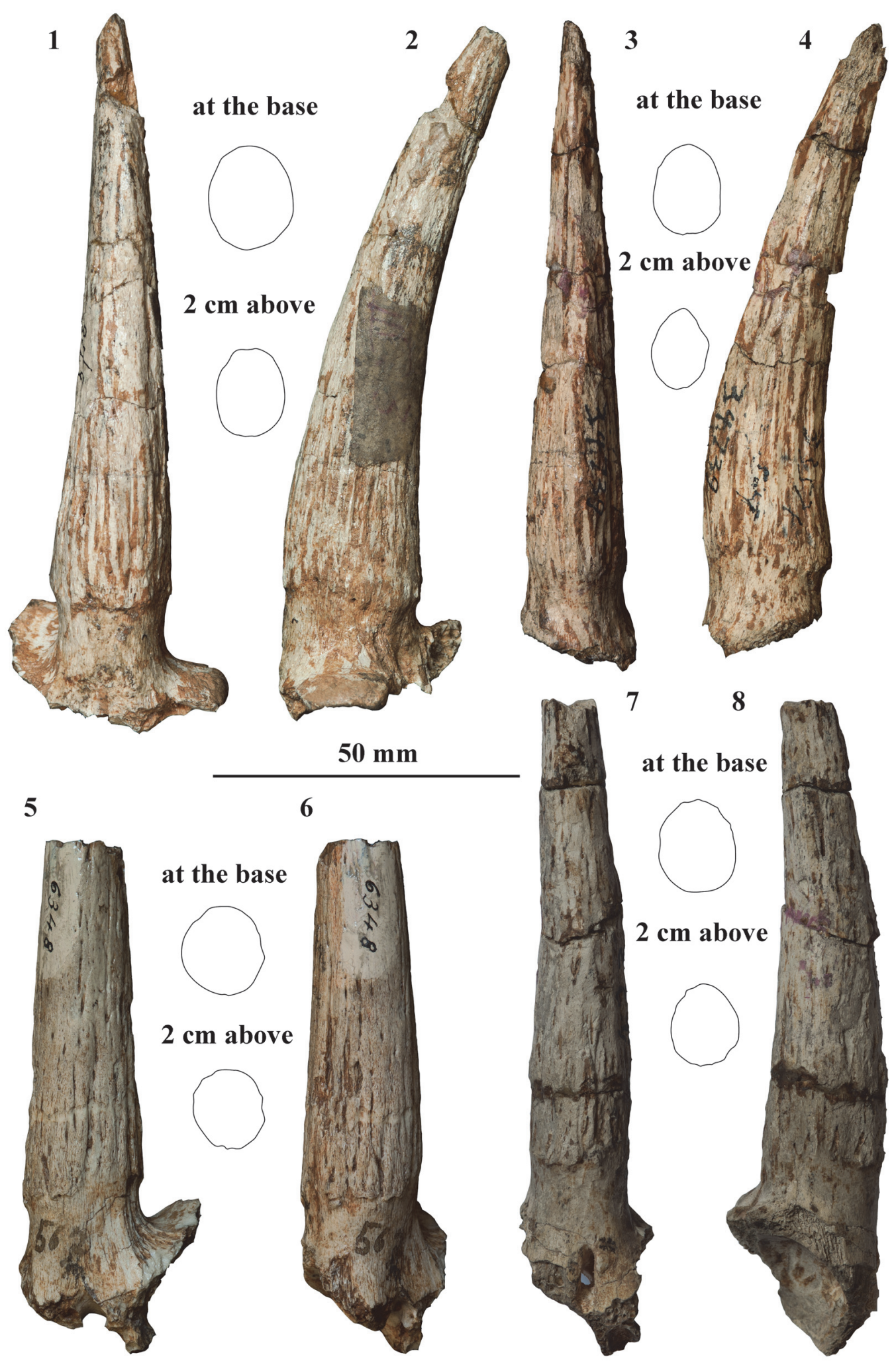

FIGURE 4. Horn cores from Qingyang, 1-4 ascribed to "Gazella" paotehensis, 5-8 ascribed to "G." dorcadoides: THP $05716,1)$ anterior view, 2) lateral view; TNP 05313, 3) anterior view, 4) lateral view; THP 06348, 5) anterior view, 6) lateral view; TNP 03875,7 ) anterior view, 8) lateral view. Scale bar equals $50 \mathrm{~mm}$. 
1

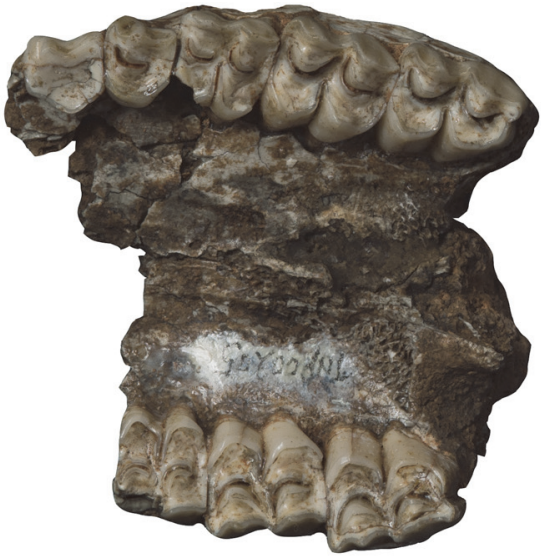

2

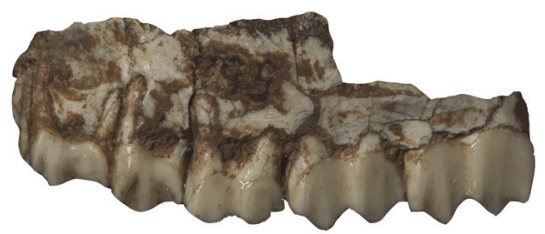

5

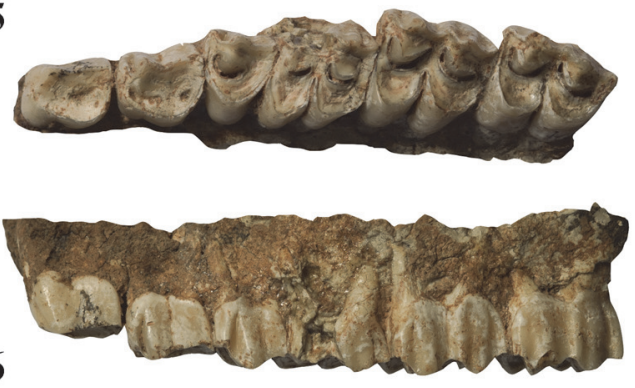

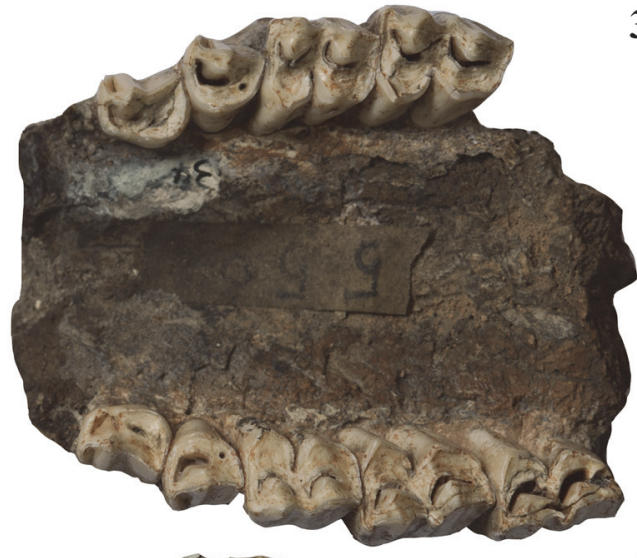

4

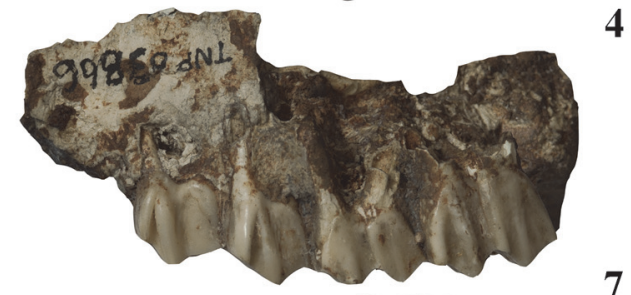

7

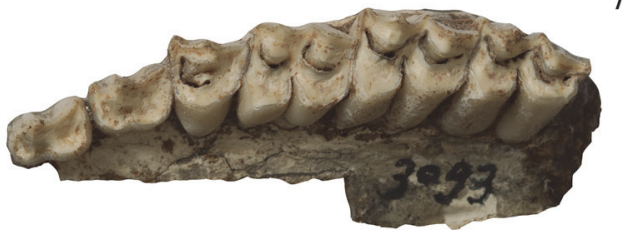

$50 \mathrm{~mm}$

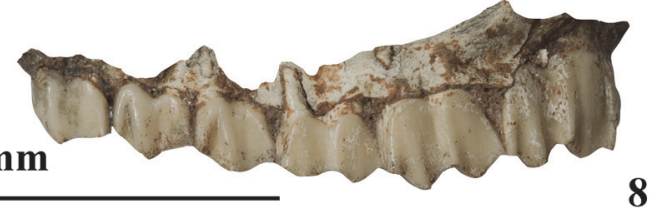

9
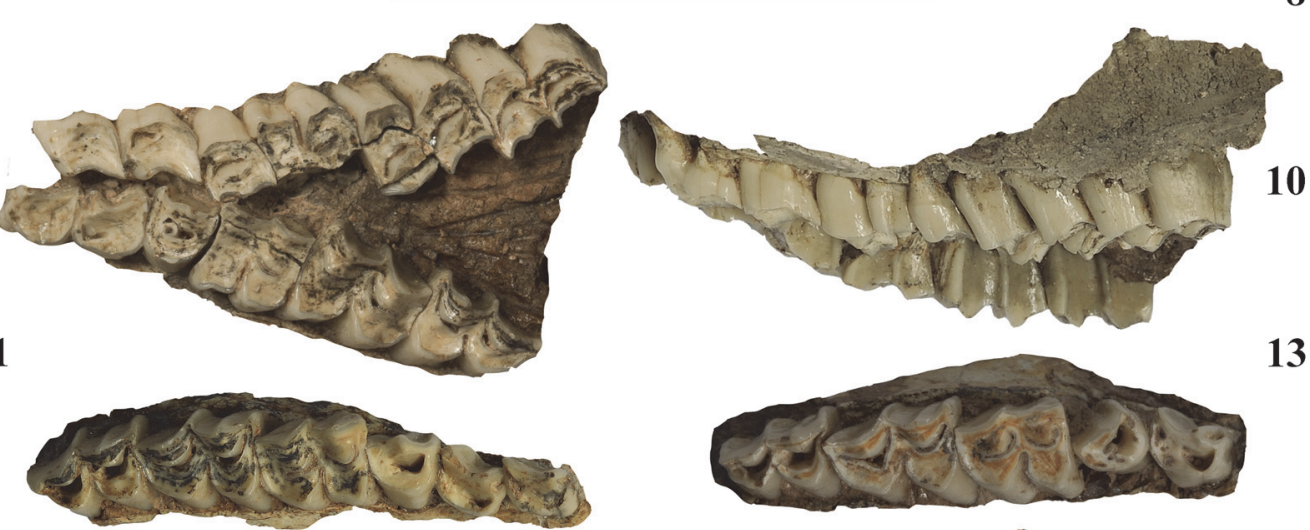

12
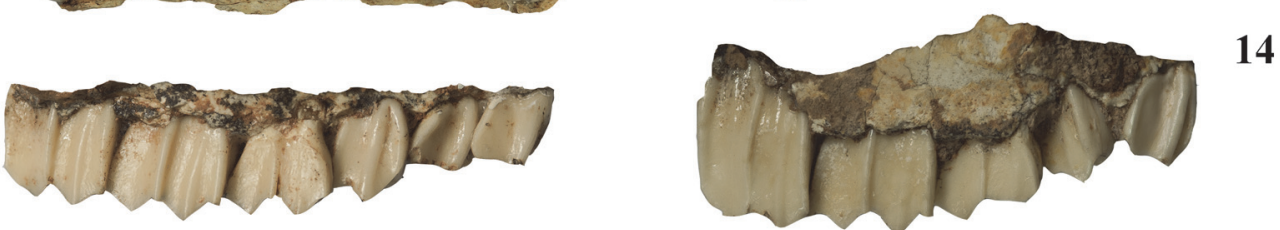

FIGURE 5. Upper maxillae from Qingyang, 1-8 ascribed to "Gazella" paotehensis, 9-14 ascribed to "G." dorcadoides: TNP 00205, 1) occlusal view, 2) left buccal view; TNP 03866, 3) occlusal view, 4) left buccal view; THP 06928, 5) occlusal view, 6) buccal view; TNP 03093, 7) occlusal view, 8) left buccal view; TNP 03793, 9) occlusal view, 10) left buccal view; TNP 03867, 11) occlusal view, 12) right buccal view; TNP 03794, 13) occlusal view, 14) right buccal view. Scale bar equals $50 \mathrm{~mm}$. 


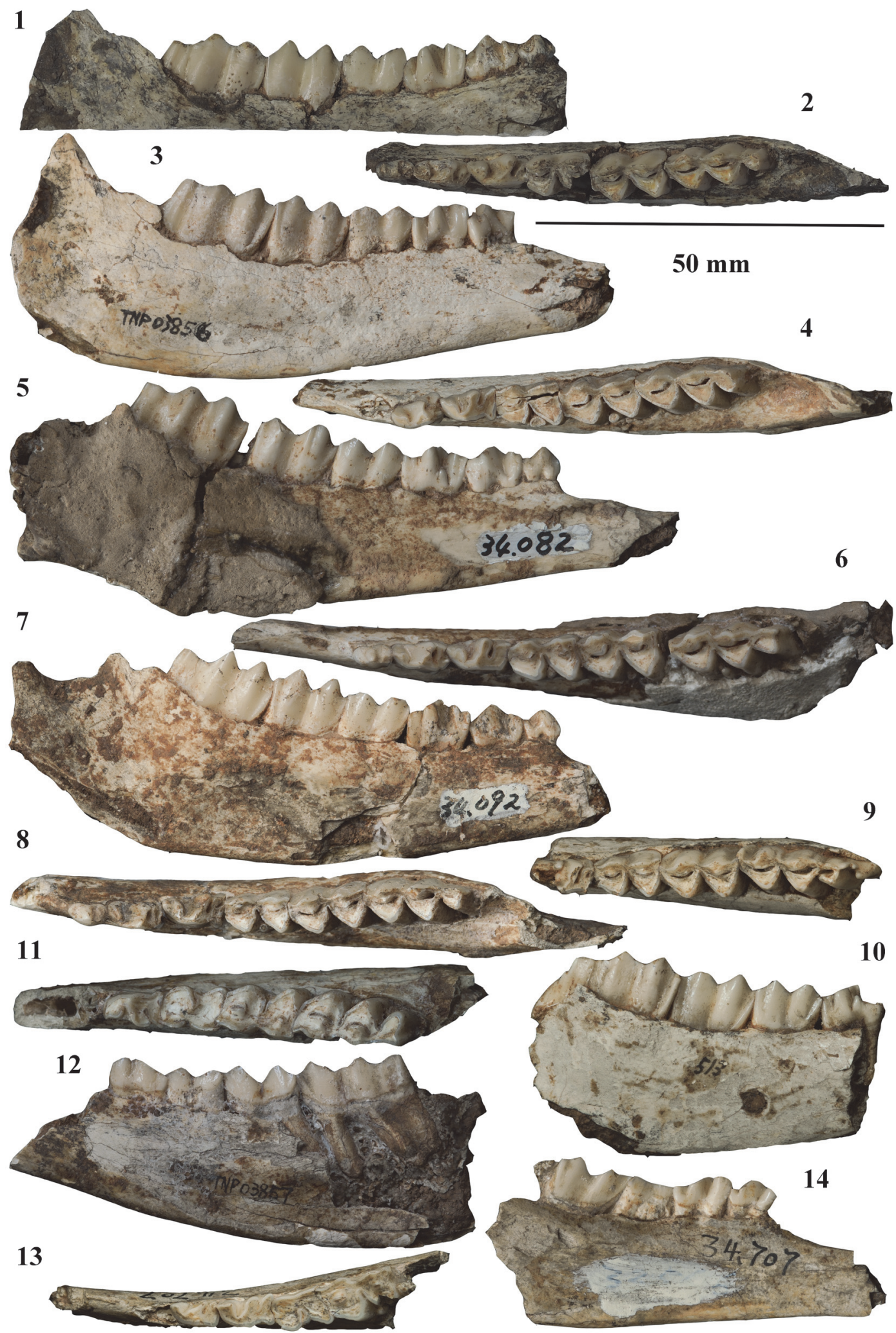

FIGURE 6. Mandibles ascribed to "Gazella" paotehensis from Qingyang, THP 07326, 1) lingual view, 2) occlusal view; TNP 03856, 3) lingual view, 4) occlusal view; TNP 03855, 5) lingual view, 6) occlusal view; TNP 03865, 7) lingual view, 8) occlusal view; THP 06863, 9) occlusal view, 10) lingual view; TNP 03857, 11) occlusal view, 12) lingual view; TNP 03876, 13) occlusal view, 14) lingual view. Scale bar equals $50 \mathrm{~mm}$. 
TABLE 1. Cranium measurements of "Gazella" paotehensis from Qingyang (mm).

\begin{tabular}{lcc}
\hline & TNP 00206 & TNP 03795 \\
\hline P2 to foramen magnum & 118.2 & - \\
lower lachrymal suture at the edge of the orbits to tip of condyle & 100.6 & - \\
foramen magnum to rear of palate in the middle & 72.0 & - \\
breadth at glenoid fossae & 56.2 & - \\
pharyngeal tubercles of basioccipital to middle of parietal & 55.8 & - \\
breadth between external auditory meatus & 57.6 & - \\
breadth between occipital condyles & 36.7 & - \\
caudal edge of foramen magnum to projection of nuchal ligament & 23.8 & - \\
rostrocaudal length of orbit & 37.8 & 35.8 \\
dorsoventral height of orbit & 38.0 & 52.7 \\
maxillary above M3 to roof of orbits & 53.6 & - \\
length of auditory bullae & 24.3 & - \\
width of auditory bullae & 14.2 & - \\
maximum breadth between nasal & 23.9 & 8.1 \\
breadth between pharyngeal tubercles & 11.7 & 18.0 \\
internal breadth between basal pedicles & 19.8 & - \\
P2-M3 & 51.3 & - \\
P2-P4 & 29.7 & - \\
M1-M3 & 22.8 & - \\
width between bases of M1 & 25.5 & - \\
width between bases of M2 & 28.1 & - \\
\hline
\end{tabular}

dally, with their minimum distance close to the parietal-supraoccipital suture.

The supraoccipital is relatively large in proportion, and contacts the temporal laterally and the mastoid caudolaterally. The braincase is relatively short, and the dorsal outline of the cranial roof is curved in profile.

The occipital is trapezoid-shaped, with a prominent external occipital protuberance and a median ridge. The median ridge diminishes caudally quickly, with a distance to reach the dorsal margin of the foramen magnum. Each half of the occipital surface faces caudolaterally.

The basioccipital is rectangular-shaped, with anterior tuberosities ventrally expanded and posterior tuberosities slightly laterally extended. The auditory bulla is oval and much expanded, the caudal portion is more expanded than the rostral one, and the rostral portion is slightly located rostral to the anterior tuberosities of the basioccipital. The oval foramen is small, facing ventrolaterally.

The maxilla is roughly triangular in profile, and maxillary tuberosities are eminent, located at the level of the M1. The infraorbital foramen opens anteriorly with an oval tunnel, and is located at cranial level of P3 in TNP 00206 or the boundary between P2 and P3 in TNP 03795. In ventral view, the maxilla width of TNP 00206 is maximal at the level of M2 or M3, and progressively decreases rostrally. The lateral indentation at the back of the palate comes rostrally to the level of the distal lobe of M3, and the choanae open more or less at the same level as the lateral indentation.

The lachrymal is serrately sutured with the maxilla and comprises nearly the entire proportion of the preorbital fossa that is moderately developed. The ethmoidal fissure is rostrocaudally elongated. The lachrymal foramen is medium-sized and located in the inner side of the lachrymal. The lachrymal-zygomatic suture is located at the lower half of the rostral orbital rim. A noticeable crest separates the zygomatic into the dorsal and lateral parts.

Horn cores. The horn core of TNP 03795 is curved posteriorly and inserted on the dorsal rim of the orbit at a moderate angle relative to the rostrocaudal axis of the cheek teeth in profile, but the insertion angle is larger in TNP 05716. The long axis of the pedicle, as well as the horn core, is inclined toward the sagittal axis. The postcornual fossa is medium or small in size, and located slightly laterally relative to the anteroposterior axis 
TABLE 2. Horn cores measurements of "Gazella" paotehensis from Qingyang (mm).

\begin{tabular}{lccccc}
\hline $\begin{array}{c}\text { Specimen } \\
\text { number }\end{array}$ & Type & DAP & DML & LAS & Ratio \\
\hline TNP 00203 & L & 22.4 & 18.5 & $>72.5$ & 0.83 \\
& $\mathrm{R}$ & 22.5 & 18.6 & $>78.4$ & 0.83 \\
TNP 03795 & $\mathrm{L}$ & 24.7 & 20.8 & $>75.7$ & 0.84 \\
TNP 03797 & $\mathrm{R}$ & 20.2 & 16.5 & $>94.8$ & 0.82 \\
TNP 03798 & $\mathrm{R}$ & 19.8 & 16.1 & $>86.7$ & 0.81 \\
TNP 05313 & $\mathrm{L}$ & 21.2 & 16.6 & $>92.4$ & 0.78 \\
TNP 05315 & $\mathrm{R}$ & 23.2 & 18.7 & $>67.5$ & 0.81 \\
TNP 0536 & $\mathrm{L}$ & 20.8 & 16.6 & $>86.5$ & 0.80 \\
THP 05716 & $\mathrm{L}$ & 23.0 & 20.2 & $>98.2$ & 0.88 \\
THP 05724 & $\mathrm{L}$ & 23.1 & 17.1 & $>84.1$ & 0.74 \\
THP 06313 & $\mathrm{L}$ & 19.7 & 16.5 & $>85.9$ & 0.84 \\
THP 06316 & $\mathrm{L}$ & 20.3 & 15.7 & $>80.1$ & 0.78 \\
THP 06317 & $\mathrm{R}$ & 22.4 & 18.2 & $>84.1$ & 0.81 \\
THP 06318 & $\mathrm{L}$ & 22.2 & 17.0 & $>76.7$ & 0.77 \\
THP 06338 & $\mathrm{R}$ & 21.6 & 17.2 & $>88.5$ & 0.80 \\
THP 06351 & $\mathrm{R}$ & 20.8 & 16.0 & $>64.1$ & 0.77 \\
THP 06359 & $\mathrm{R}$ & 20.2 & 16.3 & $>58.7$ & 0.81 \\
THP 06384 & $\mathrm{L}$ & 21.8 & 17.4 & $>92.8$ & 0.80 \\
THP 06385 & $\mathrm{L}$ & 22.7 & 17.1 & $>86.4$ & 0.76 \\
THP 06387 & $\mathrm{R}$ & 22.6 & 17.5 & $>70.4$ & 0.78 \\
THP 06783 & $\mathrm{R}$ & 23.9 & 16.1 & $>74.7$ & 0.68 \\
THP 06841 & $\mathrm{L}$ & 23.8 & 18.4 & $>82.7$ & 0.77 \\
THP 07281 & $\mathrm{L}$ & 20.0 & 16.1 & $>77.5$ & 0.80 \\
\hline
\end{tabular}

DAP, anteroposterior diameter at the base; DML, mediolateral diameter at the base; LAS, anterior straight length, > nearly complete, missing the tip, >> far from complete; Ratio, the ratio between mediolateral and anteroposterior diameters

of the horn core. The basal cross-section is oval, and the ratio between mediolateral and anteroposterior diameters varies between 0.68 and 0.88 , with an average at 0.79 . The medial and posterior aspects at the base of the horn core are more expanded than the lateral and anterior ones, although the maximum mediolateral diameter occurs at the midpoint. The cross-section constricts rapidly, and the lateral aspect is much flatter in the upper half. The anterior straight length of the horn core reaches about $100 \mathrm{~mm}$, and it is medium-sized relative to the cranium length. The longitudinal grooves are well developed in TNP 03795. The posterior groove is the widest, and extends from the base to the preserved top. Two anterior grooves are present, and stretch from the middle to the preserved top. Several grooves occur on the lateral aspect, and diminish from the middle toward the base.

Upper teeth. Six upper teeth are measured in the Table 3. The cheek teeth row from P2 to M3 mea- sures $54.8 \mathrm{~mm}$ in TNP 03093 and $51.3 \mathrm{~mm}$ in TNP 03795, representing maximum and minimum values, respectively. The ratio between premolar and molar row lengths is relatively high and has an average of 0.75 among four maxillae. The upper cheek teeth are mesodont.

The P2 is comprised of two portions, with an eminent conical paracone and a weak metacone on the buccal surface. The lingual wall of the distal portion protrudes more lingually than that of the mesial portion. The general structure and outline of P3 are similar to that of P2, except for the occurrence of a well-developed parastyle on P3. The paracone is more developed, and the metastyle is directed more buccally on P3. The P4 is rounded triangular-shaped, with a well-developed parastyle and a less-developed mesostyle. The paracone rib is robust and conical, and the central fossa is situated more mesially and slightly buccally twisted to the mesiodistal axis. 
TABLE 3. Upper tooth measurements of "Gazella" paotehensis from Qingyang (mm).

\begin{tabular}{|c|c|c|c|c|c|c|c|c|c|c|c|c|c|c|c|}
\hline $\begin{array}{c}\text { Specimen } \\
\text { number }\end{array}$ & Type & $\mathbf{L}$ & W1 & W2 & H1 & $\mathrm{H} 2$ & $\begin{array}{l}\text { Wear } \\
\text { stage }\end{array}$ & $\begin{array}{c}\text { Specimen } \\
\text { number }\end{array}$ & Type & L & w1 & W2 & H1 & $\mathrm{H} 2$ & $\begin{array}{l}\text { Wear } \\
\text { stage }\end{array}$ \\
\hline \multirow[t]{8}{*}{ TNP 00205} & L P3 & 7.2 & 5.6 & 7.2 & 4.9 & - & & TNP 03795 & L P4 & 7.1 & 6.5 & 6.5 & 8.1 & - & \\
\hline & L P4 & 6.6 & 7.9 & 7.5 & 5.9 & - & & & L M3 & - & 7.6 & - & 9.8 & - & \\
\hline & L M1 & 9.3 & - & 9.5 & 4.9 & 4.7 & heavy & & R P2 & 7.3 & 5.0 & 5.8 & 8.2 & - & \\
\hline & L M2 & 11.5 & 9.7 & 8.7 & 6.7 & 6.9 & & & R P3 & 8.5 & 5.4 & 6.2 & 7.9 & - & \\
\hline & L M3 & 12.3 & 8.5 & 7.3 & 7.7 & 8.4 & & & R P4 & 7.0 & 6.5 & 6.7 & 8.4 & - & \\
\hline & R M1 & - & - & 9.3 & - & 4.5 & heavy & & R M2 & - & - & 8.5 & - & 8.8 & moderate \\
\hline & R M2 & 11.4 & 9.5 & 8.7 & 6.3 & 6.6 & & TNP 03866 & L P3 & 7.6 & 6.5 & 7.0 & 9.1 & - & \\
\hline & R M3 & 12.3 & 9.0 & 7.6 & 7.6 & 9.2 & & & L P4 & 7.4 & 6.8 & 6.9 & 8.3 & - & \\
\hline \multirow[t]{6}{*}{ TNP 00206} & L P2 & 8.4 & 5.8 & 6.2 & 6.1 & - & & & L M1 & 10.3 & 9.7 & 8.1 & 6.7 & 6.9 & moderate \\
\hline & L P3 & 7.4 & 5.9 & 6.5 & 5.9 & - & & & L M2 & 13.1 & 9.5 & 7.6 & 9.3 & 9.1 & \\
\hline & L P4 & 6.3 & 6.9 & 6.8 & 5.9 & - & & & R P3 & 7.7 & 6.4 & 6.7 & 8.4 & - & \\
\hline & L M1 & 8.7 & 8.8 & 8.4 & 3.8 & 4.6 & heavy & & R P4 & 7.4 & 6.6 & 6.4 & 8.6 & - & \\
\hline & L M2 & 11.0 & 9.9 & 9.5 & 7.4 & 7.3 & & & R M1 & 10.8 & 9.4 & 7.6 & 7.5 & 7.6 & moderate \\
\hline & R P3 & 7.5 & 6.0 & 6.6 & 5.8 & - & & & $\mathrm{R}$ M2 & 12.5 & 9.4 & 7.7 & 10.2 & 9.9 & \\
\hline \multirow[t]{6}{*}{ TNP 03093} & L P2 & 8.3 & 5.3 & 5.8 & 6.3 & - & & & R M3 & 13.0 & 7.9 & 6.8 & 11.4 & 12.3 & \\
\hline & LP3 & 7.7 & 5.7 & 6.0 & 6.6 & - & & THP 06928 & LP2 & 7.9 & 5.5 & 6.2 & 5.5 & - & \\
\hline & LP4 & 7.4 & 7.7 & 7.2 & 7.0 & - & & & LP3 & 8.2 & 6.6 & 6.9 & 6.5 & - & \\
\hline & L M1 & 9.9 & 8.9 & 8.2 & 5.9 & 6.5 & middle & & LP4 & 6.6 & 7.4 & 7.3 & 6.6 & - & \\
\hline & L M2 & 11.6 & 9.1 & 7.7 & 8.5 & 8.4 & & & L M1 & 8.7 & - & 9.0 & - & 5.0 & heavy \\
\hline & L M3 & 11.7 & 7.9 & 6.4 & 9.4 & 10.2 & & & L M2 & 10.6 & 9.9 & 8.9 & 7.3 & 7.3 & \\
\hline TNP 03795 & LP3 & 8.4 & 5.6 & 6.1 & 6.2 & - & & & L M3 & 11.6 & 8.5 & 7.2 & 7.6 & 7.6 & \\
\hline
\end{tabular}

L, mesiodistal length; W1, width at mesial lobe; W2, width at distal lobe; $\mathrm{H} 1$, height at the paracone; $\mathrm{H}$ 2, height at the metacone.

The M1 is square-shaped, and the paracone rib is moderately or weakly developed, whereas the metacone rib is weak but present. The mesial fossa is present, except in heavy wear (e.g., TNP 00206). The general structure and outline of M2 is similar to that of M1, but the size of $M 2$ is larger (Table 3). The paracone rib is conical buccally, whereas the metacone rib varies from conical to weak. The parastyle is well developed, and the mesostyle is slightly less developed than or similar to the parastyle. The metastyle is less developed and is directed buccally. The M2 is slightly inclined toward the mesiodistal axis, and this orientation is more marked on M3. Besides that, the M3 is narrower and longer than $\mathrm{M} 2$ because of the development of the metastyle. The paracone rib is conical, and the metacone rib varies from conical to weak. The metastyle is well developed and distobuccally directed.

Lower teeth. The cheek teeth row from $\mathrm{p} 2$ to $\mathrm{m} 3$ is $55.4 \mathrm{~mm}$ in THP 07326 and $57.1 \mathrm{~mm}$ in TNP 03865 . The ratio between lower premolar and molar row lengths is 0.63 in THP 07326, and 0.66 in TNP 03865. The lower cheek teeth are mesodont.
The p2 is plumply triangular-shaped, with the protoconid most eminent. A narrow groove occurs mesial to the protoconid, and a shallow depression is present, distal to the protoconid. The p3 is elongated triangular-shaped. The separation between the parastylid and the paraconid is in a low extent, and the valley mesial to the paraconid is closed after moderate wear. The valley between the paraconid and metaconid is open and V-shaped. The metaconid is located distal to the protoconid, and the premetacristid is inclined toward the mesiodistal axis. The valley between the metaconid and entoconid is closed at least in late middle wear. The p4 is similar to that of p3 in the occlusal outline and structure. The parastylid separates from the paraconid in early wear and fuses soon after moderate wear. The valley between the paraconid and metaconid is open, deeper $\mathrm{V}$ shaped than that of p3 from the occlusal and lingual views, and a small stylid occurs at the lingual base of the valley in TNP 03855, TNP 03865, and THP 06863. The metaconid is robust, located slightly distal to the protoconid, and surpasses the paraconid and entoconid along the buccolingual direction. The valley between the metaconid and entoconid is closed in late middle wear. The groove 
TABLE 4. Lower tooth measurements of "Gazella" paotehensis from Qingyang (mm).

\begin{tabular}{|c|c|c|c|c|c|c|c|c|}
\hline $\begin{array}{c}\text { Specimen } \\
\text { number }\end{array}$ & Type & $\mathbf{L}$ & W1 & W2 & W3 & H1 & $\mathrm{H} 2$ & $\begin{array}{l}\text { Wear } \\
\text { stage }\end{array}$ \\
\hline \multirow[t]{6}{*}{ TNP 03855} & L p2 & 5.6 & 3.2 & 3.4 & - & 4.2 & - & \\
\hline & L p3 & 8.2 & 3.2 & 4.5 & - & 5.8 & - & \\
\hline & L p4 & 9.2 & 3.9 & 5.5 & - & 7.1 & - & \\
\hline & L m1 & 9.8 & 6.2 & 6.7 & - & 6.7 & 6.4 & moderate \\
\hline & L m2 & 11.5 & 7.2 & 7.3 & - & 8.6 & 8.3 & \\
\hline & $\mathrm{L} \mathrm{m} 3$ & 15.9 & 6.7 & 6.4 & 4.0 & 9.4 & 8.3 & \\
\hline \multirow[t]{5}{*}{ TNP 03856} & L p3 & 7.8 & 3.2 & 4.1 & - & 5.3 & - & \\
\hline & L p4 & 8.5 & 4.1 & 5.2 & - & 5.7 & - & \\
\hline & L m1 & 9.2 & 5.9 & 6.6 & - & 5.1 & 4.8 & middle \\
\hline & L m2 & 10.7 & 6.7 & 6.2 & - & 8.6 & 8.3 & \\
\hline & $\mathrm{L} \mathrm{m} 3$ & 14.7 & 6.1 & 6.1 & 3.9 & 9.9 & 8.3 & \\
\hline \multirow[t]{4}{*}{ TNP 03857} & R p4 & 8.7 & 4.2 & 5.2 & - & 4.0 & - & \\
\hline & $\mathrm{R} \mathrm{m} 1$ & 8.4 & 6.4 & 6.7 & - & 3.7 & 3.8 & heavy \\
\hline & $\mathrm{R}$ m2 & 10.7 & 7.3 & 7.6 & - & 5.4 & 5.1 & \\
\hline & $\mathrm{R}$ m3 & 16.1 & 7.2 & 6.9 & 5.0 & 6.6 & 6.2 & \\
\hline \multirow[t]{6}{*}{ TNP 03865} & L p2 & 5.6 & 2.9 & 3.1 & - & 4.2 & - & \\
\hline & L p3 & 7.4 & 3.2 & 3.7 & - & 6.6 & - & \\
\hline & L p4 & 9.3 & 3.6 & 4.9 & - & 7.4 & - & \\
\hline & L m1 & 9.3 & 5.4 & 5.7 & - & 6.4 & 6.4 & moderate \\
\hline & L m2 & 11.0 & 6.3 & 6.2 & - & 9.1 & 9.1 & \\
\hline & $\mathrm{L} \mathrm{m} 3$ & 14.9 & 6.1 & 6.0 & 3.6 & 9.5 & 8.9 & \\
\hline \multirow[t]{4}{*}{ TNP 03876} & L p3 & 6.8 & 3.4 & 4.0 & - & 3.7 & - & \\
\hline & L p4 & 8.6 & 4.5 & 4.7 & - & 3.7 & - & \\
\hline & $\mathrm{L} \mathrm{m} 1$ & 7.0 & 5.7 & 6.1 & - & 2.8 & 3.0 & heavy \\
\hline & L m2 & - & 6.5 & - & - & 6.4 & 6.9 & \\
\hline \multirow[t]{4}{*}{ THP 06863} & L p4 & - & - & 4.8 & - & 6.7 & - & \\
\hline & L m1 & 9.7 & 5.5 & 5.9 & - & 6.7 & 7.3 & moderate \\
\hline & L m2 & 11.2 & 6.3 & 6.1 & - & 8.2 & 7.5 & \\
\hline & L m3 & 15.7 & 6.2 & 5.6 & 3.7 & 8.6 & 7.4 & \\
\hline \multirow[t]{6}{*}{ THP 07326} & L p2 & 5.4 & 2.7 & 3.0 & - & 3.7 & - & \\
\hline & L p3 & 7.4 & 3.1 & 3.7 & - & 5.5 & - & \\
\hline & L p4 & 8.4 & 3.3 & 4.7 & - & 6.3 & - & \\
\hline & L m1 & - & 5.9 & - & - & 6.9 & 7.1 & middle \\
\hline & L m2 & 10.7 & 6.2 & 6.1 & - & 8.4 & 8.3 & \\
\hline & L m3 & 13.9 & 5.9 & 5.5 & 2.8 & 9.1 & 8.9 & \\
\hline
\end{tabular}

L, mesiodistal length; W1, width at mesial (first) lobe; W2, width at distal (second) lobe; W3, width at third lobe, especially for m3; H1, height at the protoconid for lower premolar, height at the metaconid for lower molar; H2, height at the entoconid for lower molar.

mesial to the hypoconid is faint in TNP 03855 and THP 07326, but distinct in TNP 03857, TNP 03856, TNP 03865, TNP 03876, and THP 06863.

The $\mathrm{m} 1$ is rectangular-shaped. The metaconid rib is bumped, whereas the entoconid rib is less developed. The central fossette of $\mathrm{m} 1$ is present in middle wear, and the ectostylid is well developed.
The junction between two lobes is clearly concave from the lingual view and forms a V-shaped middle indentation from the occlusal view. The $\mathrm{m} 2$ is similar to that of $\mathrm{m} 1$ in the occlusal outline and structure. The metaconid rib is well developed, but the entoconid rib is moderately developed. A weak goat fold is present in THP 07326 and TNP 03856, 
and the parastylid is moderately developed in TNP 03856, TNP 03855, TNP 03865, and THP 06863. A weak metastylid is present in TNP 03855, TNP 03856, TNP 03865, THP 06863, and THP 07326. The ectostylid is moderately developed, small and low in TNP 03855, TNP 03857, TNP 03865, TNP 03876, THP 06863, and relatively high in TNP 03856. The third lobe of the $\mathrm{m} 3$ is much smaller, aligning with the mesial two lobes. The metaconid rib is bumped, and the entoconid rib is at least moderately developed. The parastylid is well developed and buccally directed, and the metastylid is weakly developed. A distal stylid is present in TNP 03855, TNP 03857, TNP 03865 and THP 06863, and that of THP 06863 is well developed, forming a buccal fold.

\section{Discussion of "Gazella" paotehensis}

"Gazella" paotehensis was established by Teilhard de Chardin and Young (1931), and its holotype is a partial frontal with horn cores and a palate with upper teeth. A second individual was also mentioned: a palate associated with a mandible. Three characters are listed in "G." paotehensis as differing from "Gazella" cf. gaudryi, a species later recognized as "G." dorcadoides by Bohlin $(1935,1939): 1)$ the longer, incurved backward and strongly divergent horn core; 2) distinctly brachydont teeth, but "advanced" lower p4; 3) its larger size (Teilhard de Chardin and Young, 1931).

Although no additional material from southeastern Shanxi is ascribed to "Gazella" paotehensis, Teilhard de Chardin and Trassaert (1938) emphasized its validity, however, "G." paotehensis was not included in their taxonomic framework. In their statement in 1938 the type was based on the associated horn cores and lower jaw. This point contrasted with the previous description in 1931 and was strongly doubted by Bohlin (1939). In the opinion of Bohlin, the lower jaw depicted in Plate VII figure 4 (Teilhard de Chardin and Young, 1931), because of its larger size, cannot be associated with the maxilla in Plate VII figure 3 under the same species. Furthermore, this jaw may belong to ?Tragoreas lagrelii Bohlin, 1935, and was later attributed to the genus Dorcadoryx Teilhard de Chardin and Trassaert, 1938 (Bohlin, 1935, 1939; Chen, 2005).

The lower jaw together with the entire original type series of "Gazella" paotehensis seems crucial, however, it is absent at the collection of Institute of Vertebrate Paleontology and Paleoanthropology. Only a left astragalus, RV 31044 is still present at the collection but it was not mentioned in the origi- nal manuscript (we provide photos and a short comparison with the astragalus of "G." dorcadoides in the Appendix). Based on the measurements from the illustrations, this jaw may have longer lower molars than those of "G." paotehensis but fits within the range of Dorcadoryx (Figure 7.3). Although unconvinced about the species "G." paotehensis, Bohlin $(1935,1939)$ referred some material from Shanxi and Gansu to "Gazella" sp. (?= "G." paotehensis), which is a larger type than his "G." gaudryi and consistent with the first and third diagnoses of "G." paotehensis given by Teilhard de Chardin and Young (1931). In the second diagnosis, the lower p4 of "Gazella" sp. illustrated in Plate XII figures 6-7 (Bohlin, 1935) also shows a complication: the valley between the paraconid and metaconid seems closed. However, in lingual view (Figure 2.4) a weak slit appears at the top and separates the mesial extension of the metaconid; in occlusal view (Figure 2.5) the parastylid endures in a more advanced wear stage than the distalextending part but is similar to a constrained and rounded area. The former looks like an unworn tip, and the latter seems like the paraconid. A completely transitioned series of complicated $\mathrm{p} 4$ is figured by Bohlin (1939: page 94), and a lingual stylid is often present in the valley between the paraconid and metaconid of "Gazella" sp., which was also noticed by Bohlin (1939: page 96). Three mandibles from Qingyang (TNP 03855, TNP 03865, and THP 06863) also show the same structure, and therefore the morphology of lower p4 differs from that illustrated by Teilhard de Chardin and Young (1931). The second diagnosis should be revised to state that the valley between the paraconid and metaconid is usually open, with a high frequency of the presence of a lingual stylid tending to form a complete lingual wall.

Despite the fact that the lower jaw differs metrically and morphologically from the holotype, the name "Gazella" paotehensis is still valid, and the neotype is raised due to the loss of comparable type series. The specimens studied by Teilhard de Chardin and Young (1931) are from Luzigou, Baode, Shanxi (Locality 3), indicated by the astragalus RV 31044, however, no more specimens from the same locality were discovered or studied. Thus considering the preserved completeness and ease of access, the specimen M 3956, studied by Bohlin (1939) is chosen as the neotype of " $G$." paotehensis, which also shows our respect for his contribution to the taxonomy of late Miocene gazelles.

"Gazella" dorcadoides Schlosser, 1903 


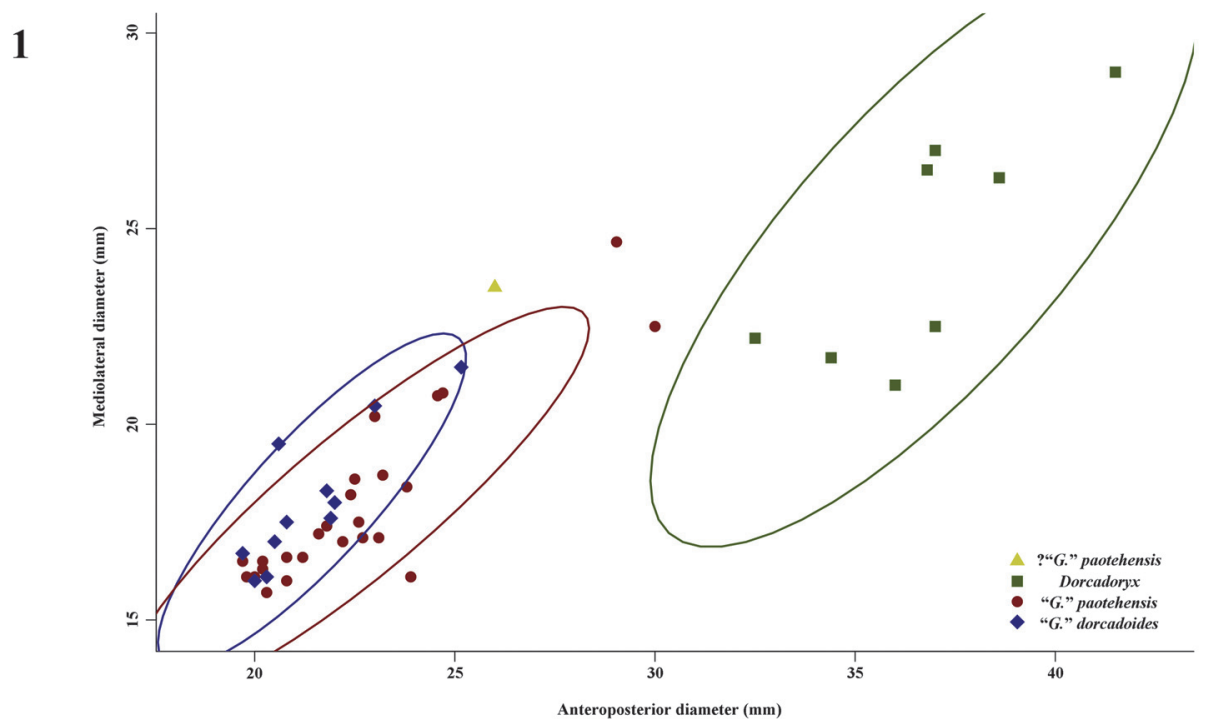

2

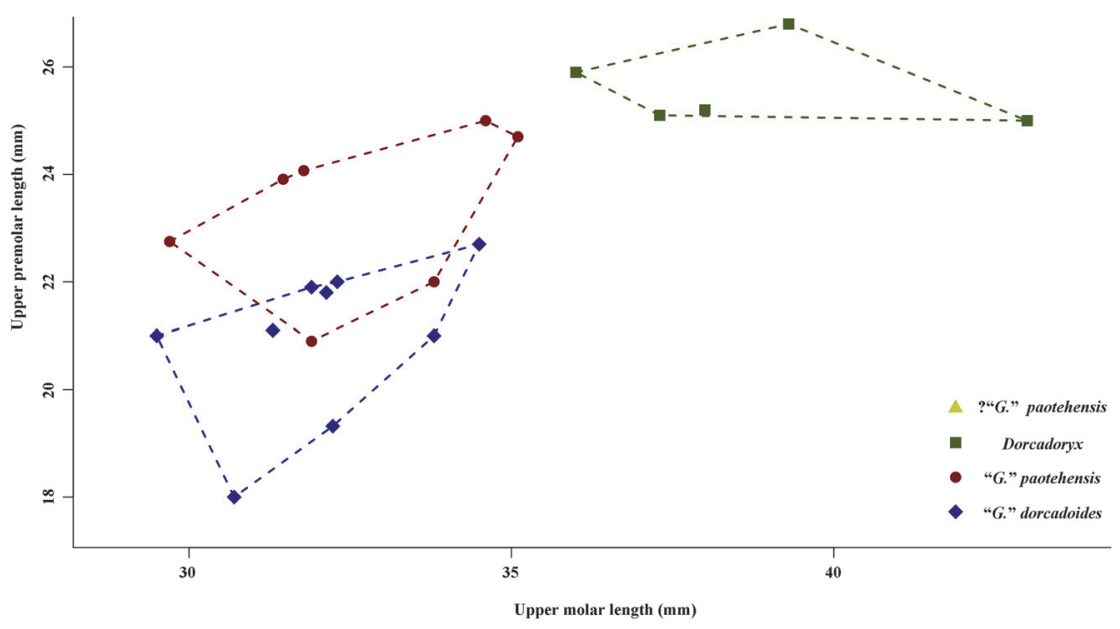

3

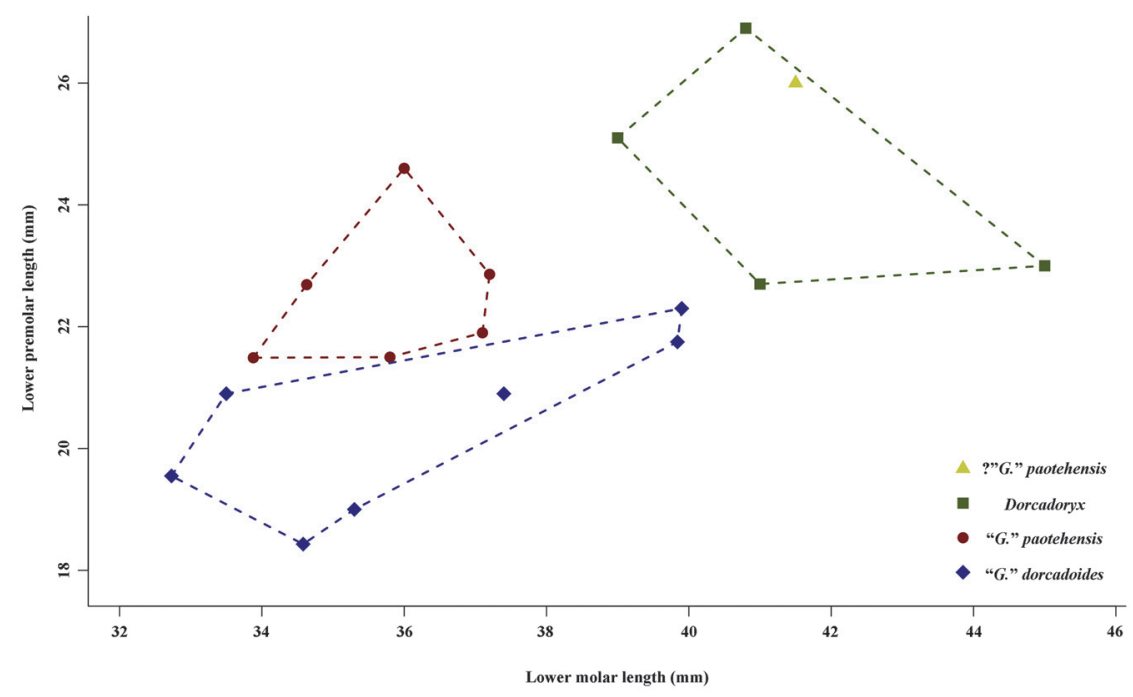

FIGURE 7. Comparisons of measurements (in $\mathrm{mm}$ ) between "Gazella" paotehensis and "G." dorcadoides, 1) anteroposterior and mediolateral basal diameters of horn cores (with $90 \%$ confidence ellipses, 2) upper premolar and molar lengths (with convex hull polygons), 3) lower premolar and molar lengths (with convex hull polygons). Data from Teilhard de Chardin and Young (1931), Bohlin (1935), Li and Chi (1964), Chen (1997a, 2005), and Li (2015). 


\section{Synonyms}

Gazella dorcadoides in part Schlosser, 1903, Plate XI figures 1, 2, 6, 7, pages 129-131 (except BSPG 1903 XII 725-727)

Gazella dorcadoides-ähnlich Antilopen Bohlin, 1935, text-figures 74-77, Plate XII figures 10-23, pages $90-96$

Gazella dorcadoides type Bohlin, 1939, text-figures $33-40,49-50$, Plate I figures 8-10, 12-13, Plate II figures 4-5, 10-13, pages 107-113

Gazella dorcadoides Li and Chi, 1964, Plate I figures 1-6, Plate II figures 6-7, pages 290-293

Type series. According to Schlosser (1903), the type series of "Gazella" dorcadoides contain 30 fragmentary mandibles, seven fragmentary maxillae, and about 22 isolated upper and lower teeth, however, due to the Second World War, only eight fragmentary lower teeth (BSPG 1903 XII 65, 721727) are still kept in Bayerische Staatssammlung für Paläontologie und Geologie in Munich, Germany. Since Schlosser described the material collected from Chinese drugstores, the exact localities are unknown.

Lectotype. BSGP 1903 XII 721, a left m3 (illustrated in Schlosser, 1903, Plate XI figure 6), without an accurate locality. The lectotype was proposed by Solounias (1981).

Emended differential diagnosis. Approximately same size as "Gazella" gaudryi, and hornless in females; horn cores slightly divergent, differing from moderately divergent horn cores in "G." paotehensis, and strongly inclined, differing from moderately inclined horn cores in "G." gaudryi and "G." paotehensis; hind part of dorsal outline of the parietal of "G." dorcadoides rapidly inclined in lateral view, differing from the curved outline of " $G$." gaudryi and "G." paotehensis; teeth of "G." dorcadoides more hypsodont than contemporary "G." gaudryi and "G." paotehensis; lower molars with the only one ectostylid present on $\mathrm{m} 1$, differing from the continuous ectostylids present on $m 1-m 3$ in "G." gaudryi and "G." paotehensis, and lower molars with flat lingual walls, differing from outbowed lingual walls in "G." gaudryi and "G." paotehensis.

Referred material. One cranium: TNP 03854, partial cranium with right facial part and horn cores preserved; three maxillae: TNP 03793, left P2-M3, right P2-M3; TNP 03794, right P3-M3; TNP 03867, right $\mathrm{P} 2-\mathrm{M} 3$; 10 mandibles: TNP 03858, left p2-m3; TNP 03859, right p3-m3; TNP 03860, right p3-m3; TNP 03861, left p4-m3; TNP 03862, right p2-m2; TNP 03863, left p2-m3; TNP 03864, right $\mathrm{p} 4-\mathrm{m} 1$; TNP 03868, right $\mathrm{m} 1-\mathrm{m} 3$; THP
03028, left p2-m3; THP 07000, right p4-m3; six horn cores: TNP 00204, two; TNP 03875, right; THP 06324, left; THP 06348, right; THP 06349, right; THP 06380, right; four horn core fragments: TNP 03792, TNP 05314, TNP 05385, THP 05756 (Figures 4, 5, 8, 9; Tables 5-7).

\section{Description}

Cranium. The right part of the face and two horn cores are preserved in TNP 03854, with part of molar rows still present in the alveoli. In ventral view the lateral palatal indentations are probably at the level of the distal lobe of $M 3$, and in caudal view the frontal is porous, and the cribriform plate is large and oval-shaped.

Horn cores. Only TNP 03854 preserves the horn core inserted on the cranium with a small angle in profile, but the apparent wide separation and moderate divergence may be influenced by the distortion. The postcornual fossa is small in size and located slightly medially relative to the anteroposterior axis of the horn core. The basal cross-section is subcircular, and the average ratio between diameters is larger than 0.80 . The anterior straight length reaches about $100 \mathrm{~mm}$. No continuous grooves are present on the horn cores.

Upper teeth. The length of cheek teeth row from $\mathrm{P} 2$ to $\mathrm{M} 3$ is $51.1 \mathrm{~mm}$ in TNP 03867, and the ratio between the premolar and molar row lengths is 0.60 , with a relatively short premolar row compared to the upper teeth attributed to "Gazella" paotehensis. The upper cheek teeth are higher than those of "G." paotehensis.

The P2 is plumped, and the paracone rib is conical and slightly distobuccally directed. The P3 is similar to P2 in the occlusal outline, structure, and size (Figure 5, Table 6). The parastyle is present on P3, and the metastyle is well developed and protrudes buccally to make a more concave buccal wall. The P4 is rounded triangular-shaped, with an eminent centrally positioned paracone. The parastyle is well developed, and the central fossa is situated centrally and aligned with the mesiodistal axis.

The M1 is squared rectangular-shaped without the buccal protrusions of the parastyle and metastyle. The paracone rib of $\mathrm{M} 1$ is weak but present, whereas the metacone rib is absent. The metacone wall is at least slightly concave, and the mesostyle is weakly developed. The M2 is rectangular-shaped and larger than $\mathrm{M} 1$ in size. The paracone rib of $\mathrm{M} 2$ is columnar, but the metacone rib is absent. The parastyle is well developed, and the mesostyle is even more developed, surpassing 


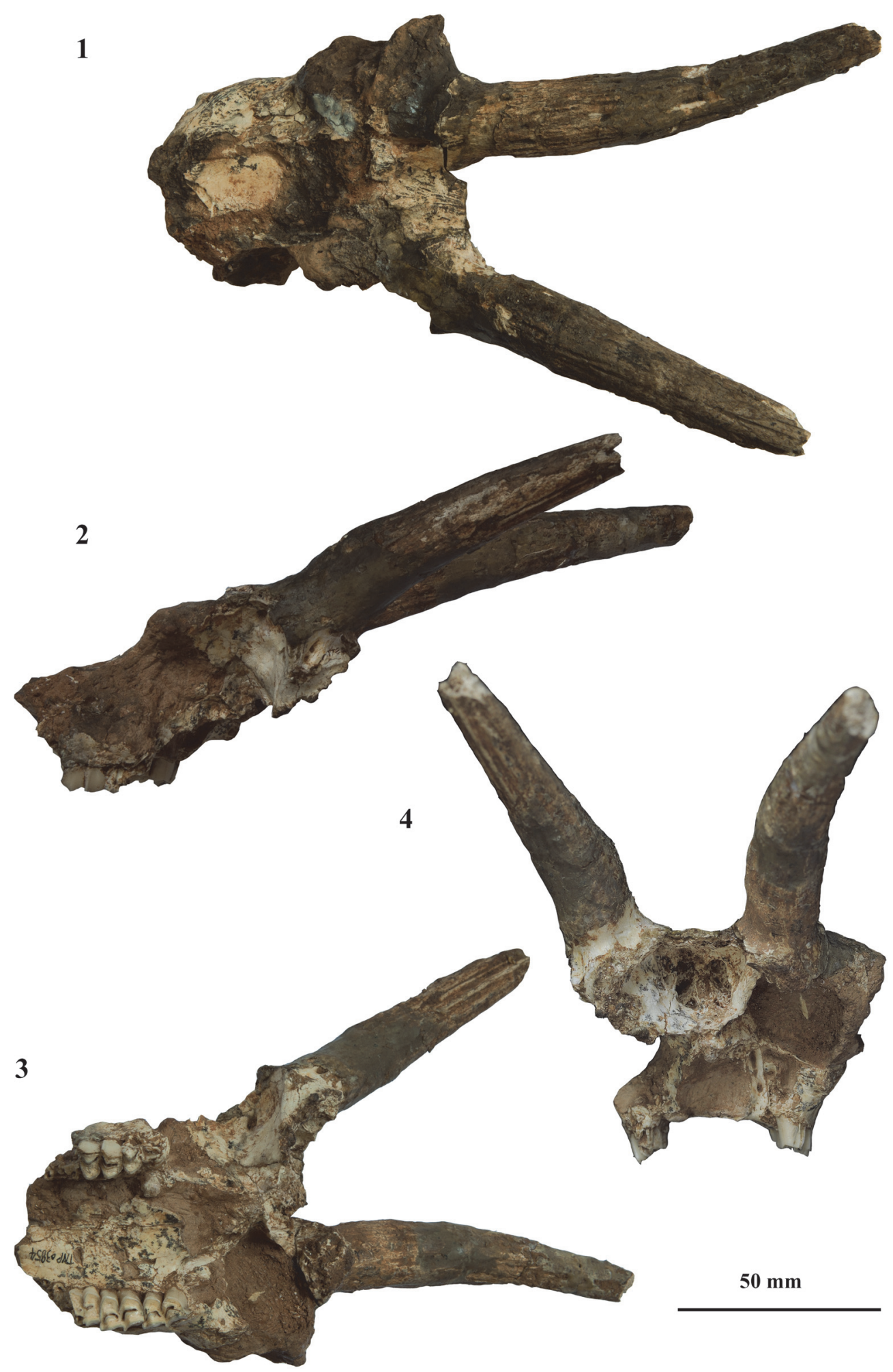

FIGURE 8. Cranium ascribed to "Gazella" dorcadoides from Qingyang, TNP 03854, 1) dorsal view, 2) left lateral view, 3) ventral view, 4) caudal view. Scale bar equals $50 \mathrm{~mm}$. 


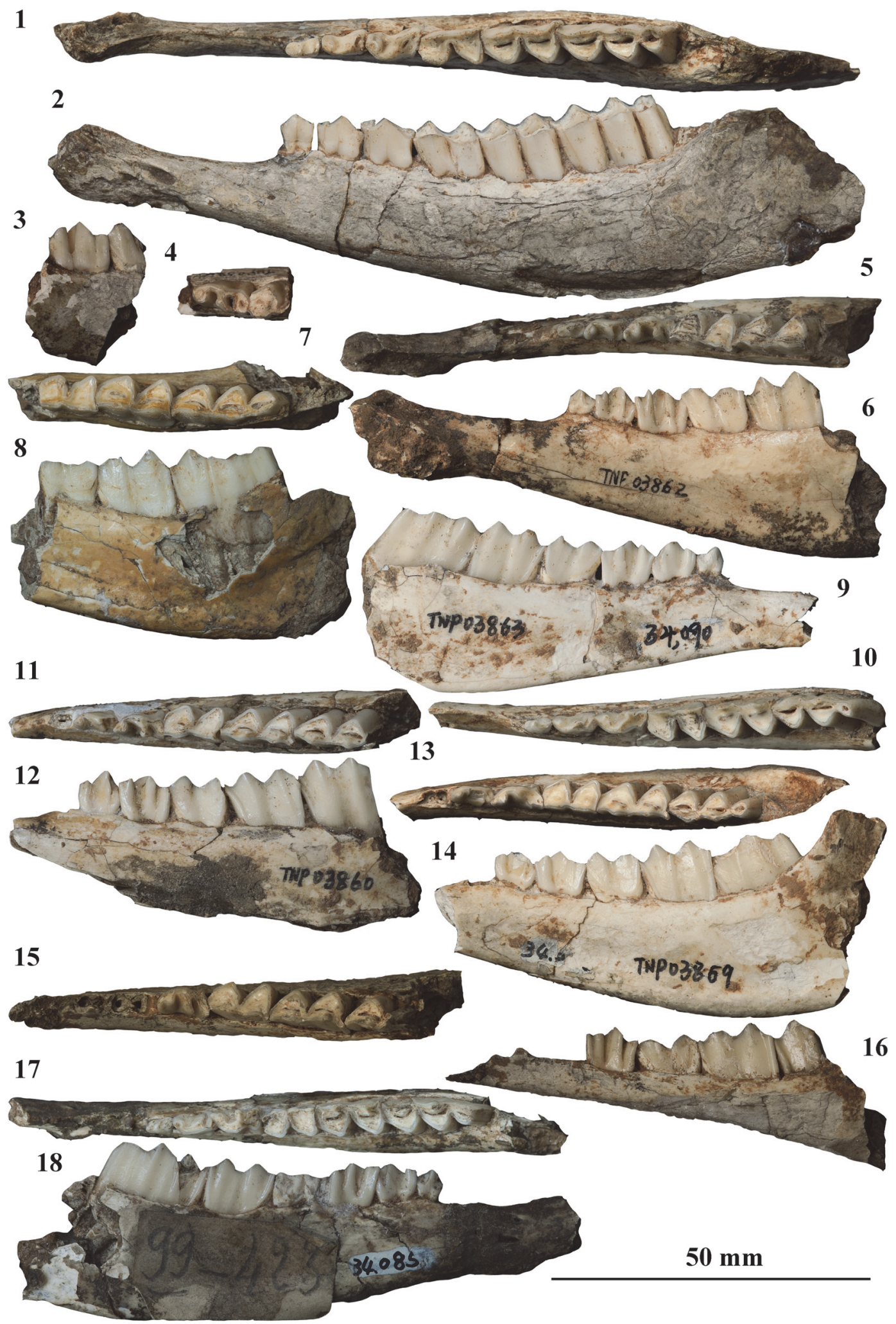

FIGURE 9. Mandibles ascribed to "Gazella" dorcadoides from Qingyang, THP 03028, 1) occlusal view, 2) left buccal view; TNP 03864, 3) lingual view, 4) occlusal view; TNP 03862, 5) occlusal view, 6) lingual view; THP 03868, 7) occlusal view, 8) lingual view; TNP 03863, 9) lingual view, 10) occlusal view; TNP 03860, 11) occlusal view, 12) lingual view; TNP 03859, 13) occlusal view, 14) lingual view; THP 07000, 15) occlusal view, 16) lingual view; TNP 03858, 17) occlusal view, 18) lingual view. Scale bar equals $50 \mathrm{~mm}$. 
TABLE 5. Horn cores measurements of "Gazella" dorcadoides from Qingyang (mm).

\begin{tabular}{cccccc}
\hline $\begin{array}{c}\text { Specimen } \\
\text { number }\end{array}$ & Type & DAP & DML & LAS & Ratio \\
\hline TNP 00204 & L & 19.7 & 16.7 & $>>40.1$ & 0.85 \\
& $\mathrm{R}$ & 19.6 & 15.7 & $>>51.2$ & 0.80 \\
TNP 03854 & $\mathrm{R}$ & 21.9 & 17.6 & $>94.9$ & 0.81 \\
TNP 03875 & $\mathrm{R}$ & 20.5 & 17.0 & $>76.2$ & 0.83 \\
THP 06324 & $\mathrm{L}$ & 20.8 & 17.5 & $>77.1$ & 0.84 \\
THP 06348 & $\mathrm{R}$ & 20.6 & 19.5 & $>>58.6$ & 0.95 \\
THP 06349 & $\mathrm{R}$ & 21.8 & 18.3 & $>>61.4$ & 0.84 \\
THP 06380 & $\mathrm{R}$ & 20.3 & 16.1 & $>79.8$ & 0.80 \\
\hline
\end{tabular}

For explanations see Table 2.

TABLE 6. Upper tooth measurements of "Gazella" dorcadoides from Qingyang (mm).

\begin{tabular}{|c|c|c|c|c|c|c|c|}
\hline $\begin{array}{c}\text { Specimen } \\
\text { number }\end{array}$ & Type & $\mathbf{L}$ & W1 & W2 & H1 & $\mathrm{H} 2$ & $\begin{array}{l}\text { Wear } \\
\text { stage }\end{array}$ \\
\hline \multirow[t]{10}{*}{ TNP 03793} & L P2 & 6.5 & 5.4 & 5.6 & 6.1 & - & \\
\hline & L P3 & 6.6 & - & 5.9 & - & - & \\
\hline & L P4 & 6.8 & 6.5 & 6.1 & - & - & \\
\hline & L M1 & 9.1 & 9.2 & 9.2 & - & - & heavy \\
\hline & L M2 & 11.3 & 9.9 & 8.5 & - & - & \\
\hline & L M3 & 11.9 & 8.3 & 6.2 & - & - & \\
\hline & R P2 & 6.8 & 5.4 & 5.9 & - & - & \\
\hline & R P3 & 6.9 & 5.8 & - & - & - & \\
\hline & R M2 & 11.6 & 9.6 & - & - & - & \\
\hline & R M3 & 11.9 & 8.6 & 6.7 & - & - & \\
\hline \multirow[t]{5}{*}{ TNP 03794} & R P3 & 7.2 & 5.2 & 6.5 & 9.7 & - & \\
\hline & R P4 & 6.5 & - & - & - & - & \\
\hline & R M1 & 10.4 & 8.5 & 7.5 & 6.2 & 7.5 & moderate \\
\hline & $\mathrm{R}$ M2 & 12.6 & 8.2 & 7.2 & 10.2 & 8.8 & \\
\hline & R M3 & 11.2 & 6.2 & 4.8 & 13.4 & 14.3 & \\
\hline \multirow[t]{4}{*}{ TNP 03854} & L M2 & 10.9 & 9.2 & 8.3 & 7.6 & 7.7 & \\
\hline & R M1 & - & - & 8.5 & - & 3.8 & heavy \\
\hline & R M2 & 11.0 & 8.8 & 8.1 & 6.4 & 6.8 & \\
\hline & R M3 & 11.7 & 7.6 & 6.9 & 8.1 & 6.3 & \\
\hline \multirow[t]{6}{*}{ TNP 03867} & R P2 & 6.9 & 4.7 & 4.8 & 7.7 & - & \\
\hline & R P3 & 7.1 & 5.0 & 5.1 & 6.5 & - & \\
\hline & R P4 & 6.4 & 5.9 & 5.7 & 10.0 & - & \\
\hline & R M1 & 10.3 & 8.4 & 7.9 & 7.3 & 7.0 & moderate \\
\hline & R M2 & 11.6 & 7.9 & 7.1 & 8.7 & 8.3 & \\
\hline & R M3 & 11.8 & 7.1 & 5.3 & 9.5 & 7.9 & \\
\hline
\end{tabular}

For explanations see Table 3.

the paracone rib along the linguobuccal direction. Due to the development of the mesostyle, the paracone and metacone walls of M2 are more concave than that of M1. The M3 is similar to $M 2$ in occlusal outline and structure. The paracone rib of
M3 is columnar, whereas only a weak metacone rib occurs at the low portion of TNP 03794, and no metacone rib occurs in the other three maxillae. The paracone and metacone walls are clearly concave with the eminences of the parastyle, meso- 
TABLE 7. Lower tooth measurements of "Gazella" dorcadoides from Qingyang (mm).

\begin{tabular}{|c|c|c|c|c|c|c|c|c|c|c|c|c|c|c|c|c|c|}
\hline $\begin{array}{c}\text { Specimen } \\
\text { number }\end{array}$ & Type & $\mathbf{L}$ & W1 & W2 & W3 & H1 & $\mathrm{H} 2$ & Wear stage & $\begin{array}{l}\text { Specimen } \\
\text { number }\end{array}$ & Type & $\mathbf{L}$ & W1 & W2 & W3 & H1 & H2 & $\begin{array}{l}\text { Wear } \\
\text { stage }\end{array}$ \\
\hline \multirow[t]{6}{*}{$\begin{array}{l}\text { TNP } \\
03858\end{array}$} & L p2 & 4.5 & 2.2 & 2.7 & - & 4.5 & - & & $\begin{array}{l}\text { TNP } \\
03862\end{array}$ & $\mathrm{R} \mathrm{m} 2$ & 11.2 & 5.8 & 5.7 & - & 8.7 & 8.7 & \\
\hline & L p3 & 6.3 & 3.1 & 3.1 & - & 6.2 & - & & \multirow{5}{*}{$\begin{array}{l}\text { TNP } \\
03863\end{array}$} & L p2 & 4.4 & 2.2 & 2.5 & - & 4.2 & - & \\
\hline & L p4 & 8.1 & 3.8 & 4.1 & - & 6.5 & - & & & L p3 & 6.6 & 2.5 & 3.1 & - & 5.4 & - & \\
\hline & L m1 & - & - & - & - & - & - & heavy & & L p4 & 8.5 & 3.5 & 3.5 & - & 6.4 & - & \\
\hline & L m2 & 10.5 & 5.4 & 5.5 & - & 7.6 & 8.3 & & & L m1 & 8.9 & 5.2 & 5.6 & - & 5.4 & 7.3 & middle \\
\hline & $\mathrm{L}$ m3 & 15.4 & - & 5.2 & 3.7 & - & 8.6 & & & L m2 & 10.6 & 5.6 & 5.7 & - & 8.2 & 8.9 & \\
\hline \multirow{5}{*}{$\begin{array}{l}\text { TNP } \\
03859\end{array}$} & R p3 & 6.5 & 2.5 & 3.3 & - & 5.2 & - & & & L m3 & 13.2 & 5.1 & 5.1 & 3.0 & 8.4 & 8.4 & \\
\hline & R p4 & 8.4 & 3.4 & 3.8 & - & 6.6 & - & & \multirow{2}{*}{$\begin{array}{l}\text { TNP } \\
03864\end{array}$} & $\mathrm{R} \mathrm{p} 4$ & 9.5 & 4.5 & 4.3 & - & 7.9 & - & \\
\hline & $\mathrm{R} \mathrm{m} 1$ & 8.7 & 5.3 & 5.5 & - & 5.9 & 6.8 & moderate & & $\mathrm{R} \mathrm{m} 1$ & - & 5.7 & - & - & 7.7 & - & moderate \\
\hline & $\mathrm{R} \mathrm{m} 2$ & 11.5 & 5.6 & 5.8 & - & 8.4 & 9.1 & & \multirow{2}{*}{$\begin{array}{l}\text { TNP } \\
03868\end{array}$} & $\mathrm{R} \mathrm{m} 1$ & 9.4 & 5.7 & 6.2 & - & 3.9 & 4.9 & heavy \\
\hline & $\mathrm{R} \mathrm{m} 3$ & 13.0 & 5.2 & 5.1 & 3.2 & - & 8.1 & & & $\mathrm{R} \mathrm{m} 2$ & 11.5 & 6.1 & 6.4 & - & 8.4 & 10.7 & \\
\hline \multirow{5}{*}{$\begin{array}{l}\text { TNP } \\
03860\end{array}$} & $\mathrm{R}$ p3 & 6.6 & 3.3 & 3.1 & - & 6.9 & - & & & $\mathrm{R}$ m3 & 16.8 & 5.7 & 5.8 & 4.2 & 14.4 & 13.9 & \\
\hline & $\mathrm{R}$ p4 & 8.5 & 3.7 & 3.6 & - & 6.9 & - & & \multirow{4}{*}{$\begin{array}{l}\text { THP } \\
03028\end{array}$} & L p2 & 5.6 & 2.6 & 3.0 & - & 4.4 & - & \\
\hline & $\mathrm{R} \mathrm{m} 1$ & 8.6 & 5.3 & 5.4 & - & 7.3 & 7.6 & moderate & & L p3 & 7.3 & 3.2 & 3.3 & - & 5.8 & - & \\
\hline & $\mathrm{R}$ m2 & 12.0 & 5.7 & 5.5 & - & 8.1 & 8.7 & & & L p4 & 9.2 & 4.4 & 5.1 & - & 6.8 & - & \\
\hline & $\mathrm{R} \mathrm{m} 3$ & - & 5.2 & 5.0 & - & 10.6 & 11.8 & & & L m1 & 10.9 & 5.1 & 5.9 & - & 5.9 & 6.7 & middle \\
\hline \multirow{3}{*}{$\begin{array}{l}\text { TNP } \\
03861\end{array}$} & $\mathrm{~L}$ m1 & - & - & - & - & - & - & moderate & & L m2 & 12.4 & 5.7 & 6.5 & - & 8.1 & 8.8 & \\
\hline & $\mathrm{L} \mathrm{m} 2$ & 11.2 & 5.8 & 5.6 & - & 13.0 & 12.9 & & & L m3 & 17.8 & 5.5 & 5.6 & 4.2 & 10.0 & 9.1 & \\
\hline & $\mathrm{L}$ m3 & 14.8 & 5.3 & 4.9 & 3.2 & 15.5 & 15.6 & & THP 07000 & $\mathrm{R} \mathrm{p} 4$ & 8.2 & 4.3 & 4.5 & - & 6.1 & - & \\
\hline \multirow{4}{*}{$\begin{array}{l}\text { TNP } \\
03862\end{array}$} & $\mathrm{R}$ p2 & 4.4 & 2.2 & 2.3 & - & 3.9 & - & & & $\mathrm{R}$ m1 & 9.2 & 5.3 & 5.9 & - & 4.6 & 5.8 & \multirow[t]{3}{*}{ middle } \\
\hline & R p3 & 6.4 & 2.9 & 2.9 & - & 5.5 & - & & & $\mathrm{R} \mathrm{m} 2$ & 11.8 & 5.5 & 5.7 & - & 6.7 & 8.3 & \\
\hline & R p4 & 7.4 & 4.1 & 3.7 & - & 6.8 & - & & & $\mathrm{R} \mathrm{m} 3$ & - & 5.2 & - & - & 8.1 & - & \\
\hline & $\mathrm{R} \mathrm{m} 1$ & 10.3 & 5.3 & 5.9 & - & 6.8 & 6.7 & moderate & & & & & & & & & \\
\hline
\end{tabular}

style, and metastyle. The mesostyle is slender and stretches buccally. The mesostyle in TNP 03794 faints at the top and strengthens from the middle to the base in buccal view. The metastyle is directed more distally and forms a strong buccal fold at the base.

Lower teeth. Ten mandibles are preserved, and the length from $\mathrm{p} 2$ to $\mathrm{m} 3$ reaches $60.6 \mathrm{~mm}$ in THP 03028 and about $52 \mathrm{~mm}$ in TNP 03858 and THP 03863. The ratio between the lower premolar and molar series is smaller than 0.60 . The lower teeth are hypsodont, higher than those of "Gazella" paotehensis.

The $\mathrm{p} 2$ is slender and short in the occlusal outline, with an eminent protoconid in buccal view. The p3 is longer and narrower than that of "Gazella" paotehensis. The paraconid and parastylid of p3 separate from each other in a low extent and fuse together in moderate wear. The metaconid stretches distally; consequently, the valley between the paraconid and metaconid is open. The valley between the metaconid and entoconid closes at least in late middle wear. The hypoconid of p3 weakly protrudes buccally in TNP 03858, TNP 03860, TNP 03863, and TNP 03869. The p4 is similar to the p3 in the occlusal outline and structure. The separation between the paraconid and parastylid may disappear in moderate wear. The valley between the paraconid and metaconid is wider V-shaped than that of $\mathrm{p} 3$. The metaconid of p4 is similar to that of p3 in TNP 03863, TNP 03869 , and THP 03028, whereas it is located at the level of the protoconid and expands mesiodistally in TNP 03858, TNP 03860, TNP 03861, TNP 03862, TNP 03864, and TNP 07000. The valley between the metaconid and entoconid is closed in late wear in TNP 03858, TNP 03860, TNP 03861, TNP 03862, and THP 07000 , or in moderate wear in TNP 03863, TNP 03864, TNP 03869, and THP 03028 . The groove mesial to the hypoconid is well developed in other material assigned to "G." dorcadoides except in TNP 03869 and THP 03028.

The $\mathrm{m} 1$ is rectangular in shape, the metaconid and entoconid ribs are weak and form a flat lingual wall. The central fossette is absent in middle wear. The ectostylid is small and low in TNP 03858, TNP 03861, TNP 03862, TNP 03863, TNP 03868, TNP 03869 , and THP 03028. The $\mathrm{m} 2$ is similar to $\mathrm{m} 1$ in the occlusal outline and structure. The metaconid and entoconid ribs are weak, and the junction area 
between the two lobes is flat, compared to the specimens ascribed to "Gazella" paotehensis. The parastylid is moderately developed and forms a slender lingual fold in TNP 03860, TNP 03861, and TNP 03869. The entostylid is moderately developed and directed distolingually. The ectostylid is not observed in any material attributed to "G." dorcadoides, which may relate to the hypsodonty. The third lobe of the $\mathrm{m} 3$ is much smaller and more buccally located than the other two lobes, and the first lobe is slightly mesiobuccally and distolingually inclined relative to the distal two lobes in TNP 03858, TNP 03861, TNP 03863, and TNP 03868. The parastylid is moderately developed and a delicate metastylid is present in TNP 03861, TNP 03863, and TNP 03869. The ectostylid is absent and the distal stylid in THP 03028 is moderately developed and distally directed.

\section{Discussion of "Gazella" dorcadoides}

"Gazella" dorcadoides was erected by Schlosser (1903) based on the following characters: in lower molars, the height is similar to the length, the metaconid and entoconid ribs are weakly developed, an ectostylid is only present on $\mathrm{m} 1$ and remains low, the third lobe of $\mathrm{m} 3$ terminates in a weak strip distally but is otherwise well rounded, the metastylid and entostylid are sometimes strongly developed but also reach only half the height of the tooth; in upper teeth, P3 and P2 display similar length and width, only the paracone carries a clear vertical rib in molars, the mesostyle is very sharp and much more developed than the parastyle and metastyle in molars, and the metastyle on M3 is converted into a wide projecting strip (Schlosser, 1903, page 129).

Only eight fragmentary lower teeth (BSPG 1903 XII 65, 721-727) are still kept in Bayerische Staatssammlung für Paläontologie und Geologie in Munich, Germany. The measurements and photographs are given in the Appendix. The specimen BSPG 1903 XII 725, figured in Plate XI figure 8 (Schlosser, 1903), is a right p4 and doubted by Bohlin for its complication. A lingual stylid occurs in the valley between the paraconid and metaconid, and this situation is not present in any material attributed to "Gazella" dorcadoides (Bohlin, 1935, 1939; $\mathrm{Li}$ and $\mathrm{Chi}, 1964)$, but it is rather a diagnostic character of "G." paotehensis. BSPG 1903 XII 726 and 727 may not belong to "G." dorcadoides because of the same reason, whereas BSGP 1903 XII 65, 721-724 match the diagnoses of "G." dorcadoides.
Bohlin (1935) agreed with Schlosser's classification and referred some material from Shanxi and Gansu to "Gazella" dorcadoides. He also suggested that the lectotype could be chosen from the specimens illustrated in Plate XI figures 1, 2, 6, and 7 of Schlosser (1903). The tooth height, fairly equal P2 and P3, absence of metacone rib, and corresponding concave metacone wall in upper molars and flat lingual wall in lower molars are emphasized to differentiate "G." dorcadoides from "G." gaudryi or "G." paotehensis, and Bohlin's diagnoses are identical to Schlosser's opinions to a large extent. Teilhard de Chardin and Trassaert (1938) ascribed the "Pontian" gazelles to "G." gaudryi subgroup, and the material ascribed to "G." dorcadoides of Schlosser (1903) was put under the title of "G." gaudryi form A together with "G." gaudryi of Bohlin (1935), whereas "G." dorcadoides of Bohlin (1935) was not included in their classification. Besides these dental characters the diagnosis mainly relied on the larger size and stronger curvature of the horn cores that are not displayed in our material attributed to "G." dorcadoides. Bohlin (1939) described some crania of "G." dorcadoides, abandoned the further differentiation among " $G$." dorcadoides, "G." dorcadoides subsp., and "G." altidens, and offered more detailed morphological differences on the teeth height. The teeth morphologies of our Qingyang material match the Schlosser and Bohlin's diagnoses of "G." dorcadoides, and its validity is also confirmed by the quantitative analysis of teeth height and new discovery from Wenqun locality (Kurtén, 1951; Li and Chi, 1964).

\section{Comparison between "Gazella" paotehensis and "G." dorcadoides}

When considering teeth hypsodonty, relative size of $\mathrm{P} 2$ and $\mathrm{P} 3$, lower premolar length ratio, number of ectostylids, and morphology of lower p4 and lower molar lingual wall, the material discovered from the Qingyang area could be clearly sorted and attributed to "Gazella" paotehensis and "G." dorcadoides. The measurements of horn core diameters and cheek tooth ratios are analyzed on Figure 7, and the comparisons between these two species are summarized and listed in Table 8.

\section{CONCLUSION}

The "Gazella" material at the Qingyang area, Gansu, China, preserved at Musée Hoangho Paiho in Tianjin is described here, and two species are identified: "Gazella" paotehensis and "G." dorcadoides. The nomenclature of "G." paotehensis Teilhard 
TABLE 8. Comparisons between "Gazella" paotehensis and "G." dorcadoides.

\begin{tabular}{|c|c|c|c|c|}
\hline Characters & References & $\begin{array}{c}\text { "Gazella" } \\
\text { paotehensis }\end{array}$ & "Gazella" dorcadoides & "Gazella" gaudryi" \\
\hline horn core divergence & $\begin{array}{l}\text { Teilhard de Chardin and } \\
\text { Young (1931) } \\
\text { Zhang and Yang (2016) }\end{array}$ & moderate & slight & slight \\
\hline $\begin{array}{l}\text { horn core inclination in } \\
\text { lateral view }\end{array}$ & Zhang and Yang (2016) & moderate & strong & moderate \\
\hline $\begin{array}{l}\text { weak posterior basal horn } \\
\text { core swelling }\end{array}$ & this study & present & absent & absent \\
\hline cranial roof & Zhang and Yang (2016) & hind part curved & hind part inclined & hind part curved \\
\hline dorsal orbital rim & this study & wide and inclined & wide and horizontal & narrow and inclined \\
\hline temporal ridges approach & this study & $\begin{array}{l}\text { strongly, equal to } \\
\text { foramen magnum }\end{array}$ & $\begin{array}{l}\text { moderately, wider than } \\
\text { foramen magnum }\end{array}$ & $\begin{array}{l}\text { moderately, wider than } \\
\text { foramen magnum }\end{array}$ \\
\hline cheek teeth hypsodonty & $\begin{array}{l}\text { Bohlin (1935, 1939) } \\
\text { Zhang and Yang (2016) }\end{array}$ & mesodont & hypsodont & mesodont \\
\hline size of upper $\mathrm{P} 2$ and $\mathrm{P} 3$ & Schlosser (1903) & equal & $\mathrm{P} 2<\mathrm{P} 3$ & $\mathrm{P} 2<\mathrm{P} 3$ \\
\hline $\begin{array}{l}\text { ratio of length of lower } \\
\text { premolar row to length of } \\
\text { lower molar row }\end{array}$ & this study & $>0.60$ & $<0.60$ & $>0.60$ \\
\hline $\begin{array}{l}\text { paraconid-metaconid } \\
\text { fusion on } \mathrm{p} 4\end{array}$ & this study & fuse in late wear & absent & absent \\
\hline $\begin{array}{l}\text { lingual stylid in the valley } \\
\text { of paraconid and } \\
\text { metaconid on p4 }\end{array}$ & this study & $\begin{array}{l}\text { present in high } \\
\text { frequency }\end{array}$ & absent & absent \\
\hline $\begin{array}{l}\text { ectostylids on lower } \\
\text { molars }\end{array}$ & this study & m1-m3 & $\mathrm{m} 1$ & m1-m3 \\
\hline lower molar lingual walls & $\begin{array}{l}\text { Schlosser (1903) } \\
\text { Zhang and Yang (2016) }\end{array}$ & outbowed & flat & outbowed \\
\hline
\end{tabular}

*Based on the morphologies of specimens M 3573, M 3575, M 3576 kept in Uppsala Universitet Evolutionsmuseet.

de Chardin and Young, 1931, is reviewed here, and due to the loss of the original material, a relatively completely preserved cranium M 3956 from Uppsala Universitet Evolutionsmuseet is selected as the neotype and the diagnosis is emended. The concept of "G." dorcadoides follows Schlosser and Bohlin, the original material from Schlosser (1903) is revised, and we provide new comparisons between "G." paotehensis and "G." dorcadoides based on our new material and personal observations.

\section{ACKNOWLEDGMENTS}

The first author is deeply thankful to M. Zheng and X. Zhang for providing the Qingyang material in this study and offering all facilities at Musée Hoangho Paiho, Tianjin, China; Dr. J.R. Ebbestad and Mr. B. Kear for offering all facilities to check the material at Uppsala Universitet Evolutionsmuseet, Sweden; Dr. G.E. Rössner to offer help at checking and photographing the material at Bayerische Staatssammlung für Paläontologie und Geologie, Germany; Dr. F. Bibi from Museum für Naturkunde, Berlin, Germany for useful discussions and suggestions; Dr. D.S. Kostopoulos and another anonymous reviewer for useful comments and suggestions; and Dr. A. Souron for editing the manuscript and sharing useful suggestions and linguistic improvements. Furthermore, we thank Dr. Z. Zhang from Institute of Vertebrate Paleontology and Paleoanthropology, China, to offer the pictures about Uppsala material and share ideas, and Mr. W. Gao for photographing the material at Musée Hoangho Paiho, Tianjin. This work is supported by the National Natural Science Foundation of China (41430102), the Strategic Priority Cultivating Research Program, CAS (XDPB05), and the Key Research Program of Frontier Sciences, CAS (QYZDY-SSW-DQC022). 


\section{REFERENCES}

Bibi, F., Bukhsianidze, M., Gentry, A.W., Geraads, D., Kostopoulos, D.S., and Vrba, E.S. 2009. The fossil record and evolution of Bovidae: state of the field. Palaeontologia Electronica 12.3.10A:11 p. http://palaeo-electronica.org/2009_3/169/index.htm

Bohlin, B. 1935. Cavicornier der Hipparion-Fauna Nord-Chinas. Palaeontologia Sinica, Series C, 9:1 166

Bohlin, B. 1939. Gazella (Protetraceros) gaudryi (Schlosser) and Gazella dorcadoides (Schlosser). Bulletin of Geological Institute Uppsala, 28:79 122.1939

Chen, G.F. 1997a. Gazella blacki Teilhard and Young, 1931 (Bovidae, Artiodactyla, Mammalia) from the Late Pliocene of Hefeng, Jingle district, Shanxi Province. Vertebrata PalAsiatica, 35:189-201.

Chen, G.F. 1997b. The genus Gazella Blainville, 1816 (Bovidae, Artiodactyla) from the Late Neogene of Yushe Basin, Shanxi Province, China. Vertebrata PalAsiatica, 35:233-249.

Chen, G.F. 2005. Dorcadoryx Teilhard et Trassaert, 1938 (Bovidae, Artiodactyla) from the Bahe Formation of Lantian, Shaanxi Province, China. Vertebrata PalAsiatica, 43:272-282.

Chen, G.F. and Zhang, Z.Q. 2009. Taxonomy and evolutionary process of Neogene Bovidae from China. Vertebrata PalAsiatica, 47:265-281.

Czyzewska, T. 1969. Remains of the Lower Pliocene Bovidae from Altan Teil, Western Mongolia. Results Polish-Mongol Palaeont Exped II. Palaeontologia Polonica, 21:95-110.

Deng, T. and Xue, X.X. 1999. Equus qingyangensis sp. nov. (Perissodactyla, Equidae) from the Early Pleistocene of Qingyang, Gansu, China. Vertebrata PalAsiatica, 37:62-74.

Dong, W. 2004. The dental morphological characters and evolution of Cervidae. Acta Anthropologia Sinica, 23 (supplement):286-295.

Gentry, A.W. 1992. The subfamilies and tribes of the family Bovidae. Mammal Review, 22:1-32. https://doi.org/10.1111/j.1365-2907.1992.tb00116.x

Gentry, A.W., Rössner, G.E., and Heizmann, E.P.J. 1999. Suborder Ruminantia, p. 225-258. In Rössner, G.E. and Heissig, K. (eds.), The Miocene Land Mammals of Europe. Verlag Friedrich Pfeil, Munich.

Gray, J.E. 1821. On the natural arrangement of vertebrose animals. The London Medical Repository Monthly Journal and Review, 15:296-310.

Hooijer, D.A. 1945. A fossil gazelle (Gazella schreuderae nov. spec.) from the Netherlands. Zoologische Mededelingen, 25:55-64.

Kurtén, B. 1951. The Chinese Hipparion fauna: a quantitative survey with comments on the ecology of the machairodonts and hyaenids and the taxonomy of the gazelles. Societas Scientiarum Fennica Commentationes Biologicae, 13:1-82.

Li, C.K. and Chi, T. 1964. Pontian mammals of Wenquan, Sinkiang. Vertebrata PalAsiatica, 8:288-300.

Li, Y.K. 2015. Gazella fossils of the Late Miocene Yangjiashan fauna from the Linxia Basin, Gansu Province. Quaternary Sciences, 35:550-560.

Jia, L.P. and Huang, W.W. 1985. The Late Palaeolithic of China, p. 211-223. In Wu, R.K. and Olsen, J.W. (eds.), Paleoanthropology and Paleolithic Archaeology in the People's Republic of China. Academic Press, New York.

Martinez, J.N. and Sudre, J. 1995. The astragalus of Paleogene artiodactyls: comparative morphology, variability and prediction of body mass. Lethaia, 28:197-209. https://doi.org/ 10.1111/j.1502-3931.1995.tb01423.x

Mateer, N.T. and Lucas, S.G. 1985. Swedish vertebrate palaeontology in China: a history of the Lagrelius Collection. Bulletin of Geological Institute University Uppsala, New Series, 11:1-24.

Mi, T.H. 1943. New finds of Late Cenozoic vertebrates. Bulletin of the Geological Society of China, 23:155-169.

Qiu, Z.X., Huang, W.L., and Guo, Z.H. 1979. Hyaenidae of the Qingyang (K'ingyang) Hipparion fauna. Vertebrata PalAsiatica, 17:200-227.

Qiu, Z.X., Huang, W.L., and Guo, Z.H. 1987. The Chinese hipparionine fossils. Palaeontologia Sinica, New Series C, 25:1-243.

Schlosser, M. 1903. Die fossilen Säugethiere Chinas nebst einer Odontographie der recenten Antilopen. Abhandlungen der Bayer ischen Akademie der Wissenschaften, 22:1-221.

Sisson, S. 1914. The Anatomy of the Domestic Animals. W.B. Saunders Company, Philadelphia.

Solounias, N. 1981. The Turolian Fauna from the Island of Samos, Greece with special emphasis on the Hyaenids and the Bovids. Contributions to Vertebrate Evolution, 6: 1-232. 
Solounias, N. 2007. Family Bovidae, p. 278-291. In Prothero, D.R. and Foss, S.E. (eds.), The Evolution of Artiodactyls. Johns Hopkins University Press, Baltimore.

Suraprasit, K., Chaimanee, Y., Chavasseau, O., and Jaeger, J.J. 2015. Middle Miocene bovids from Mae Moh Basin, Northern Thailand: the first record of the genus Eotragus from Southeast Asia. Acta Palaeontologica Polonica, 60:67-78. https://dx.doi.org/10.4202/ app.2012.0061

Teilhard de Chardin, P. and Trassaert, M. 1938. Cavicornia of South-Eastern Shansi. Palaeontologia Sinica, New Series C, 6:1-99.

Teilhard de Chardin, P. and Young, C.C. 1931. Fossil mammals from the Late Cenozoic of Northern China. Palaeontologia Sinica, Series C, 9:1-66.

Vrba, E.S. 1985. African Bovidae: Evolutionary events since the Miocene. South African Journal of Science, 81:263-266.

Wilson, D.E. and Reeder, D.M. 2005. Mammal Species of the World. A Taxonomic and Geographic Reference (3 ${ }^{\text {rd }}$ edition). Johns Hopkins University Press, Baltimore.

Zhang, Z.Q., Gentry, A.W., Kaakinen, A., Liu, L.P., Lunkka, J.P., Qiu, Z.D., Sen, S., Scott, R., Werdelin, L., Zheng, S.H., and Fortelius, M. 2002. Land mammal faunal sequence of the late Miocene of China: new evidence from Lantian, Shaanxi Province. Vertebrata PalAsiatica, 40:165-176.

Zhang, Z.Q., Kaakinen, A., Liu, L.P., Lunkka J.P., Sen, S., Gose, W.A., Qiu, Z.D., Zheng, S.H., and Fortelius, M. 2013. Mammalian Biochronology of the Late Miocene Bahe Formation, p. 187-202. In Wang, X.M., Flynn, L.J., and Fortelius, M. (eds.), Fossil Mammals of Asia: Neogene Biostratigraphy and Chronology. Columbia University Press, New York.

Zhang, Z.Q. and Yang, R. 2016. Morphology and taxonomy of Gazella (Bovidae, Artiodactyla) from the Late Miocene Bahe Formation, Lantian, Shaanxi Province, China. Vertebrata PalAsiatica, 54:1-20. 


\section{APPENDIX}

A left astragalus, RV 31044 was attributed to "Gazella" paotehensis by Teilhard de Chardin and Young (1931), still kept in the IVPP collection. Comparing with V 2915 (a right astragalus of "G." dorcadoides from Li and Qi, 1964), RV 31044 is larger than V 2915 in size, especially in the lateral length, medial length and distal width (Appendix Table 1), which indicate that "G." paotehensis may have had a larger body mass (Martinez and Sudre, 1995). There is a tentative middle crest in the proximal trochlea of RV 31044 and V 2915. In lateral view, the distal astragalo-calcaneal facet of V 2915 is more expanded, approaching the dorsal surface, whereas that of RV 31044 is slightly laterally elevated. In medial view, a proximal crest occurs in V 2915, and the corresponding area in RV 31044 is flat.

APPENDIX TABLE 1. Astragalus measurements of "Gazella" paotehensis and "G." dorcadoides $(\mathrm{mm})$.

\begin{tabular}{lcc}
\hline \multicolumn{1}{c}{ species } & $\begin{array}{c}\text { "G." paotehensis } \\
\text { RV 31044 }\end{array}$ & $\begin{array}{c}\text { "G.” dorcadoides } \\
\text { V 2915 }\end{array}$ \\
\hline lateral length & 26.3 & - \\
proximal width & 14.5 & 14.4 \\
dorso-plantar height & 14.1 & 13.1 \\
medial length & 24.4 & 22.4 \\
distal width & 15.7 & 13.8 \\
\hline
\end{tabular}

APPENDIX TABLE 2. Lower teeth measurements of "Gazella" dorcadoides ascribed by Schlosser (1903) (mm).

\begin{tabular}{ccccccccc}
\hline $\begin{array}{c}\text { Specimen } \\
\text { number }\end{array}$ & Type & L & W1 & W2 & W3 & H1 & H2 & $\begin{array}{c}\text { Wear } \\
\text { stage }\end{array}$ \\
\hline 1900 XII 65 & R m1 & 11.0 & 5.2 & 5.4 & & - & - & moderate \\
& R m2 & 13.0 & 5.2 & 4.8 & & - & - & moderate \\
1900 XII 721 & L m3 & - & & 4.8 & 2.8 & - & - & moderate \\
1900 XII 722 & L m2 & 13.6 & 6.8 & 6.4 & & 15.0 & 15.8 & moderate \\
& L m3 & 15.0 & 5.2 & 4.7 & - & - & - & moderate \\
1900 XII 723 & R m1 & 12.7 & 5.7 & 5.7 & & - & 13.8 & moderate \\
1900 XII 724 & L m3 & 16.5 & 6.6 & 6.2 & 4.0 & 9.0 & 9.2 & middle* \\
1900 XII 725 & R p4 & 9.1 & 3.7 & 4.5 & & 6.8 & & moderate \\
1900 XII 726 & L p4 & 9.1 & 4.4 & 4.5 & & 7.6 & & moderate \\
1900 XII 727 & ? L p4 & & 4.3 & & & 7.4 & & moderate \\
\hline
\end{tabular}

${ }^{*}$ middle wear in later wear stage than moderate wear. 


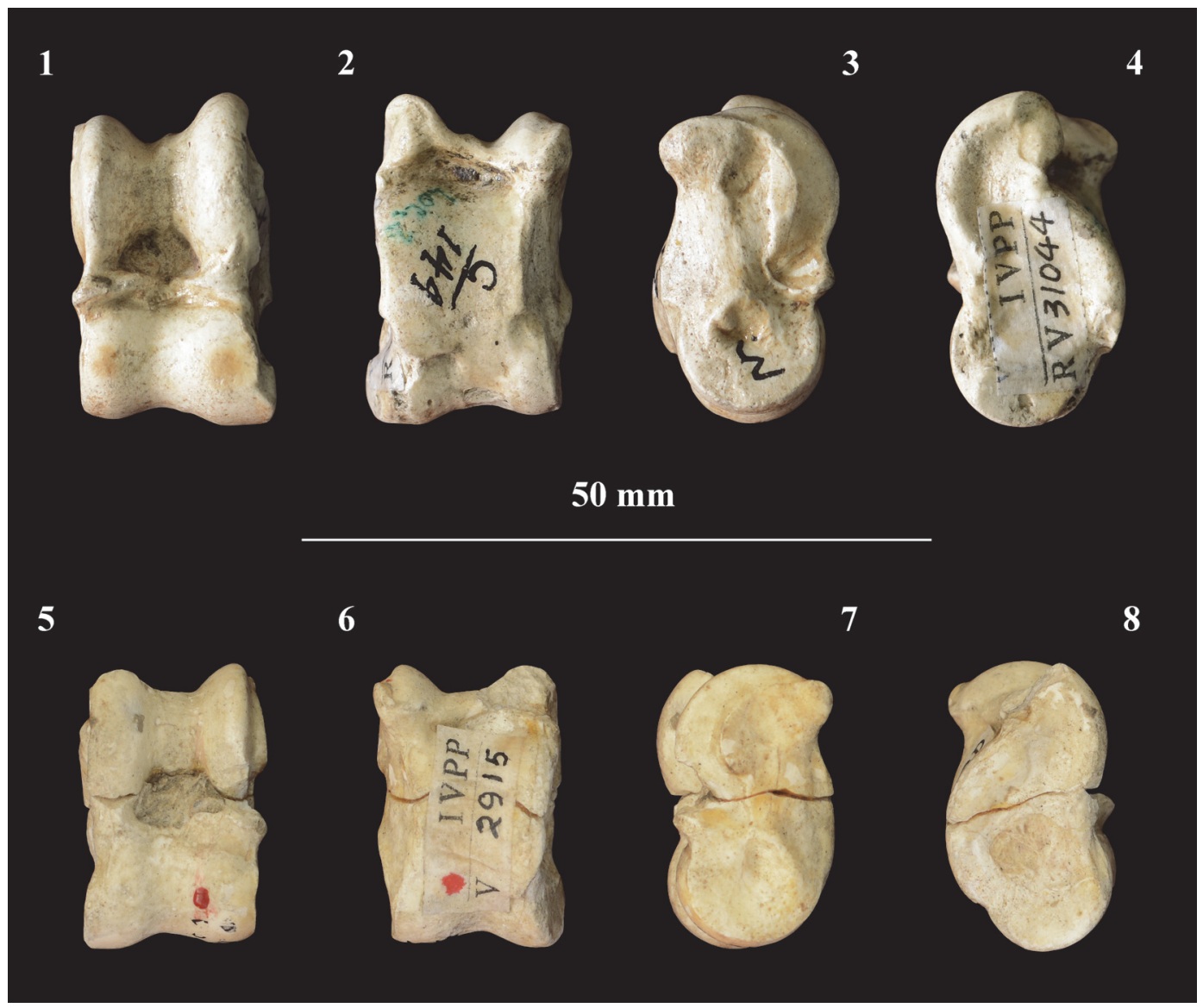

APPENDIX FIGURE 1. Astragali of "Gazella" paotehensis and "G." dorcadoides, 1-4 for "G." paotehensis, 5-8 for "G." dorcadoides: RV 31044, 1) dorsal view, 2) ventral view, 3) medial view, 4) lateral view; V 2915, 5) dorsal view, 6) ventral view, 7) medial view, 8) lateral view. Scale bar equals $50 \mathrm{~mm}$. 


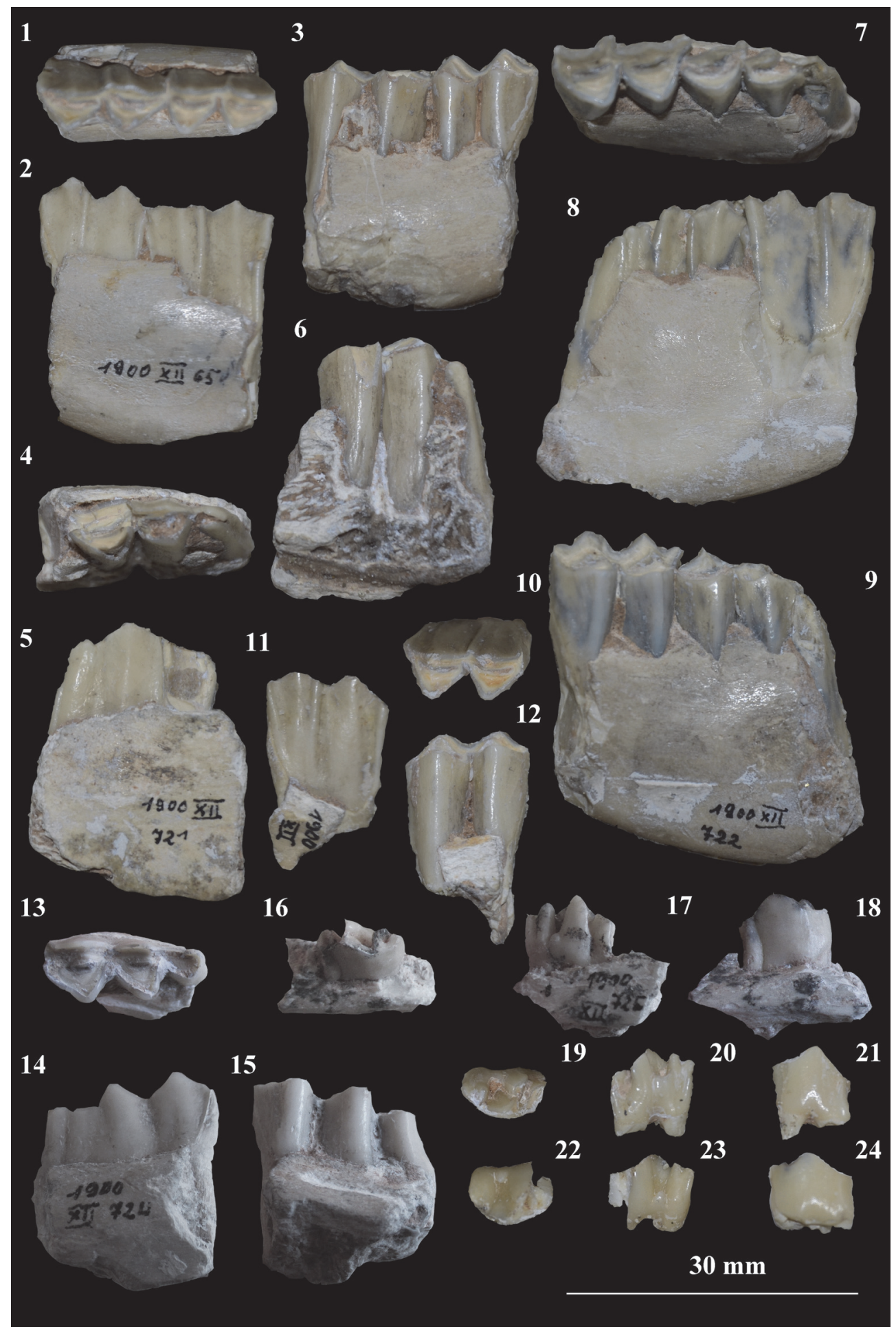

APPENDIX FIGURE 2. Lower teeth of "Gazella" dorcadoides ascribed by Schlosser (1903), 1-15 for "G." dorcadoides, 16-24 revised as "G." paotehensis: BSPG 1903 XII 65, 1) occlusal view, 2) lingual view, 3) buccal view; BSPG 1903 XII 721, 4) occlusal view, 5) lingual view, 6) buccal view; BSPG 1903 XII 722, 7) occlusal view, 8) lingual view, 9) buccal view; BSPG 1903 XII 723, 10) occlusal view, 11) lingual view, 12) buccal view; BSPG 1903 XII 724, 13) occlusal view, 14) lingual view, 15) buccal view; BSPG 1903 XII 725, 16) occlusal view, 17) lingual view, 18) buccal view; BSPG 1903 XII 726, 19) occlusal view, 20) lingual view, 21) buccal view; BSPG 1903 XII 727,22 ) occlusal view, 23) lingual view, 24) buccal view. Scale bar equals $30 \mathrm{~mm}$. 